\title{
THE PLANETARY HEALTH EDUCATION FRAMEWORK
}
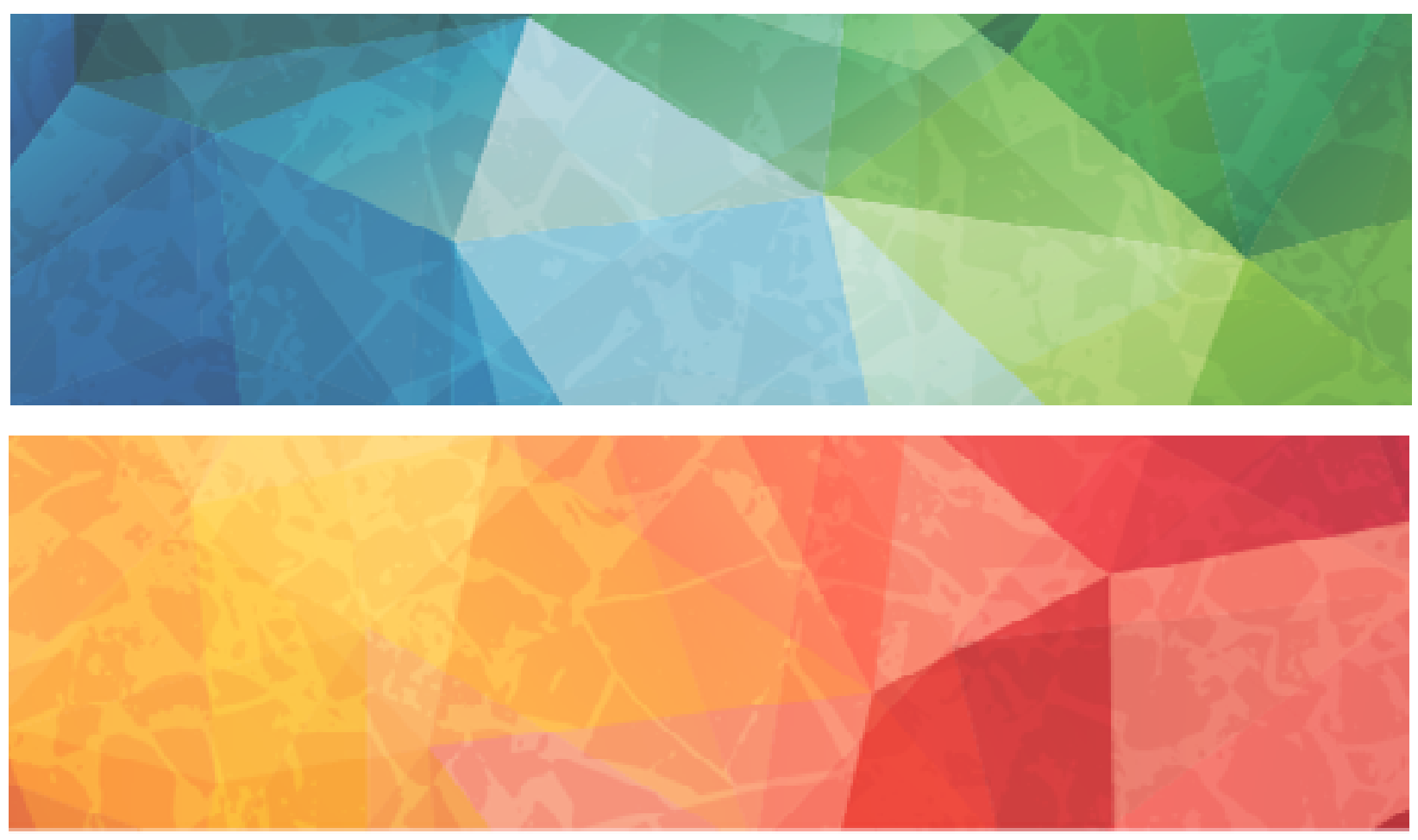

Editors

Carlos A. Faerron Guzman

Teddie Potter 
The Planetary Health Education Framework is a project of the Planetary Health Alliance (planetaryhealthalliance.org). The Planetary Health Alliance is a consortium of over 250 partners from around the world committed to understanding and addressing the human health impacts of global environmental change.

\section{EDITORS}

Carlos A. Faerron Guzman, MD, MSc, Associate Director of the Planetary Health Alliance, Assistant Professor at the University of Maryland, Baltimore, Graduate School, and Director General of the InterAmerican Center for Global Health, Costa Rica

Teddie Potter, PhD, RN, FAAN, Clinical Professor and Director of Planetary Health, School of Nursing, University of Minnesota, Minneapolis, United States

\section{CO-AUTHORS}

A. Alonso Aguirre, Environmental Science and Policy, George Mason University Fairfax, Virginia, United States

Barbara Astle, School of Nursing, Trinity Western University, Langley, British Columbia, Canada

Enrique Falceto de Barros, Universidade Federal do Rio Grande do Sul, World Organization of Family Doctors, Caxias do Sul, Brazil

Brett R. Bayles, Global Public Health, School of Health and Natural Sciences, Dominican University of California, San Rafael, California, United States

Moses Chimbari, School of Nursing and Public Health, University of KwaZulu-Natal, City of Johannesburg, Gauteng, South Africa

Naglaa El-Abbadi, Nutrition Epidemiology and Data Science, Tufts University, Boston, Massachusetts, United States

Jessica Evert, Child Family Health International, University of California San Francisco, Oakland, California, United States

Carlos A. Faerron-Guzmán, Planetary Health Alliance, Boston, Massachusetts, United States, University of Maryland, Baltimore and Centro Interamericano para la Salud Global, Costa Rica

Finola Hackett, Cumming School of Medicine, University of Calgary, Calgary, Alberta, Canada

Courtney Howard, School of Medicine, University of Calgary, Dahdaleh Institute for Global Health Research, Calgary, Alberta, Canada

Jonathan Jennings, Health In Harmony, Portland, Oregon, United States

Amy Krzyzek, Partnership Health Center, Missoula, Montana, United States

Jessica LeClair, School of Nursing, University of Wisconsin-Madison, Madison, Wisconsin, United States

Filip Maric, Health and Care Sciences, UiT The Arctic University of Norway, Tromso, Norway

Olwenn Martin, Global Challenges, Brunel University London, Middlesex, England, United Kingdom

Odipo Osano, School of Environmental Studies, University of Eldoret, Eldoret, Kenya

Jonathan Patz, Population Health Science, University of Wisconsin-Madison, Madison, Wisconsin, United States

Teddie Potter, School of Nursing, University of Minnesota, Minneapolis, Minnesota, United States

Nicole Redvers, School of Medicine and Health Sciences, University of North Dakota, Grand Forks, North Dakota, United States

Noortje Trienekens, Health In Harmony, Portland, Oregon, United States

Sarah Walpole, Newcastle University, Newcastle Hospitals, Newcastle upon Tyne, Tyne and Wear, England, United Kinddom

Lynda Wilson, School of Nursing, University of Alabama at Birmingham, Birmingham, Alabama, United States

Chenchen Xu, School of Medicine, University of Ottawa, Ottawa, Ontario, Canada

Matthew Zylstra, Organisation for Noetic Ecology, Plettenberg Bay, South Africa 


\section{Table of Contents}

Acknowledgements

Introduction

The process of creating the Framework

The Framework description and design

The Planetary Health Education Framework

Domain: Interconnection within Nature

Domain: The Anthropocene and Health

Domain: Systems Thinking / Complexity-based

26

Approaches in Planetary Health

Domain: Equity and Social Justice

Domain: Movement Building and Systems Change

Moving Forward

Key Definitions

References

52

Annex 


\section{$\infty$}

\section{Acknowledgements}

Thank you to our reviewers for their critical support of this project.

A warm thank you to the other members of the Planetary Health Alliance staff team who have contributed to the development of this anthology, specifically Sam Myers, Marie Studer, Jeremy Pivor, Max Zimberg, Joanna Wagner, and a special thank you to Arielle Blacklow for her copy editing efforts.

Thank you to the Lancet Planetary Health for publishing our work.

To the Planetary Health Alliance network, a deep appreciation for contributing countless ideas and feedback throughout this project, especially to Dr. John Latta, Dr. Katharina Wabnitz, Dr. Tatiana de Camargo, and Lewin Han for their extensive commentary on initial drafts of this framework.

The editor would personally like to thank all of the authors for their support and wisdom over the course of this 18-month project.

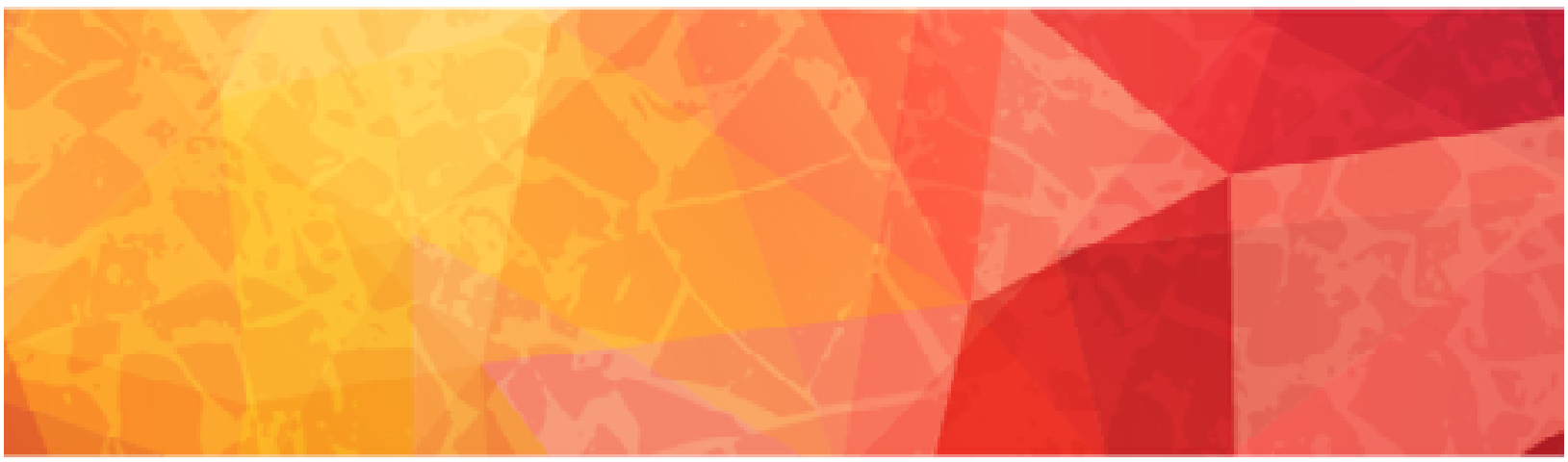




\section{THE PLANETARY HEALTH EDUCATION FRAMEWORK}

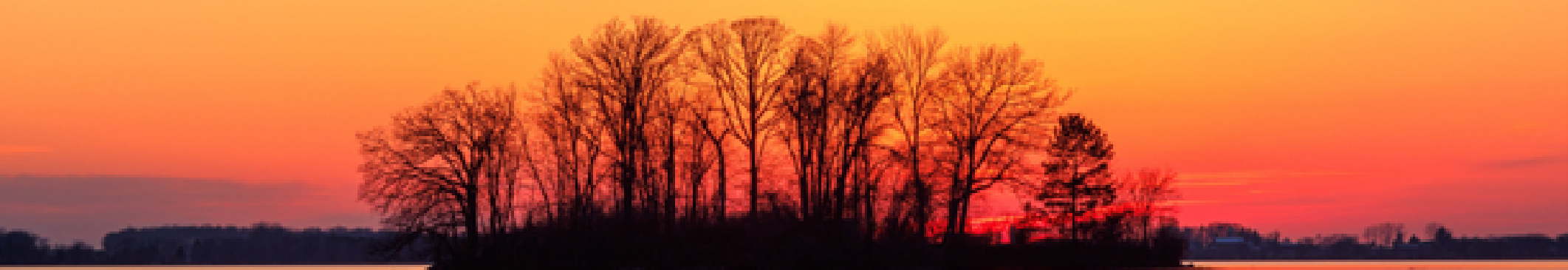




\section{c}

\section{INTRODUCTION}

There is no doubt the ongoing assault of Earth's natural systems threatens the health of current and future generations. In a business-as-usual scenario, climate change, poor air quality, soil degradation, altered biogeochemical cycles, and overexploitation of marine and terrestrial biodiversity threaten to collapse civilization as we know it. Socially and economically disadvantaged communities throughout the world face a greater risk of these negative consequences. The COVID-19 syndemics (Horton 2020), the intensification of the hurricane and typhoon seasons, the expansion of fires in Australia, the American West, the Pantanal and Siberia (IPCC 2007), in addition to the worst locust outbreak in 70 years in East Africa (Peng 2020), are a sample of the impacts humanity could increasingly encounter in decades to come. These and other global events will become more frequent if our current environmental, demographic, and hyperconsumption trends remain.

Nevertheless, there is reason for hope. Amidst this turmoil, we are also presented with an opportunity to transform the systems and values that sustain life on the planet. The sense of urgency in the face of converging crises has brought forward unprecedented attention to the interconnectedness of human societies and the biosphere, the need for global solidarity, large-scale coordination for science-driven solutions, and collective action.

Amidst these intertwining and pressing realities of environmental and health challenges, educational institutions are uniquely positioned to contribute to achieving the transformations needed for a healthier future by incorporating Planetary Health Education in their curricula. Planetary Health Education across all levels and disciplines will equip and enable learners with the necessary knowledge, skills, values, and attitudes to drive transdisciplinary and mutually reinforcing actions that protect and restore Planetary Health and achieve the UN Sustainable Development Goals. As stated by the Accelerating Education for the SDGs in Universities report, never has it been more urgent to "greatly expand society's capacity to solve complex challenges." Although we recognize that Planetary Health Education is essential for all ages and all global citizens, this particular framework is designed for learners at the entry point of higher education (i.e., general undergraduate education at universities and colleges). This level is roughly equivalent to level 6 of the 2011 version of the International Standard Classification of Education structure. 


\section{c}

As a proximate outcome, this framework aims to guide the education of global citizens (Hovland 2014), practitioners, and professionals able and willing to address the complex Planetary Health challenges of our world today. As a more distal outcome, the framework can inspire all peoples across the globe to create, restore, steward, and conserve healthy ecosystems for a thriving human civilization. We envisage that the framework will contribute to positive outcomes for the biosphere, overcoming the Planetary Health challenges before us.

Although we characterize Planetary Health as a distinct field of practice, this framework builds on and acknowledges previous scientific movements and fields such as conservation medicine, ecohealth, geohealth, and one health. It also recognizes the invaluable contributions made by traditional and contemporary Indigenous knowledge systems, especially those that have long understood the interconnectedness between humans and Nature.

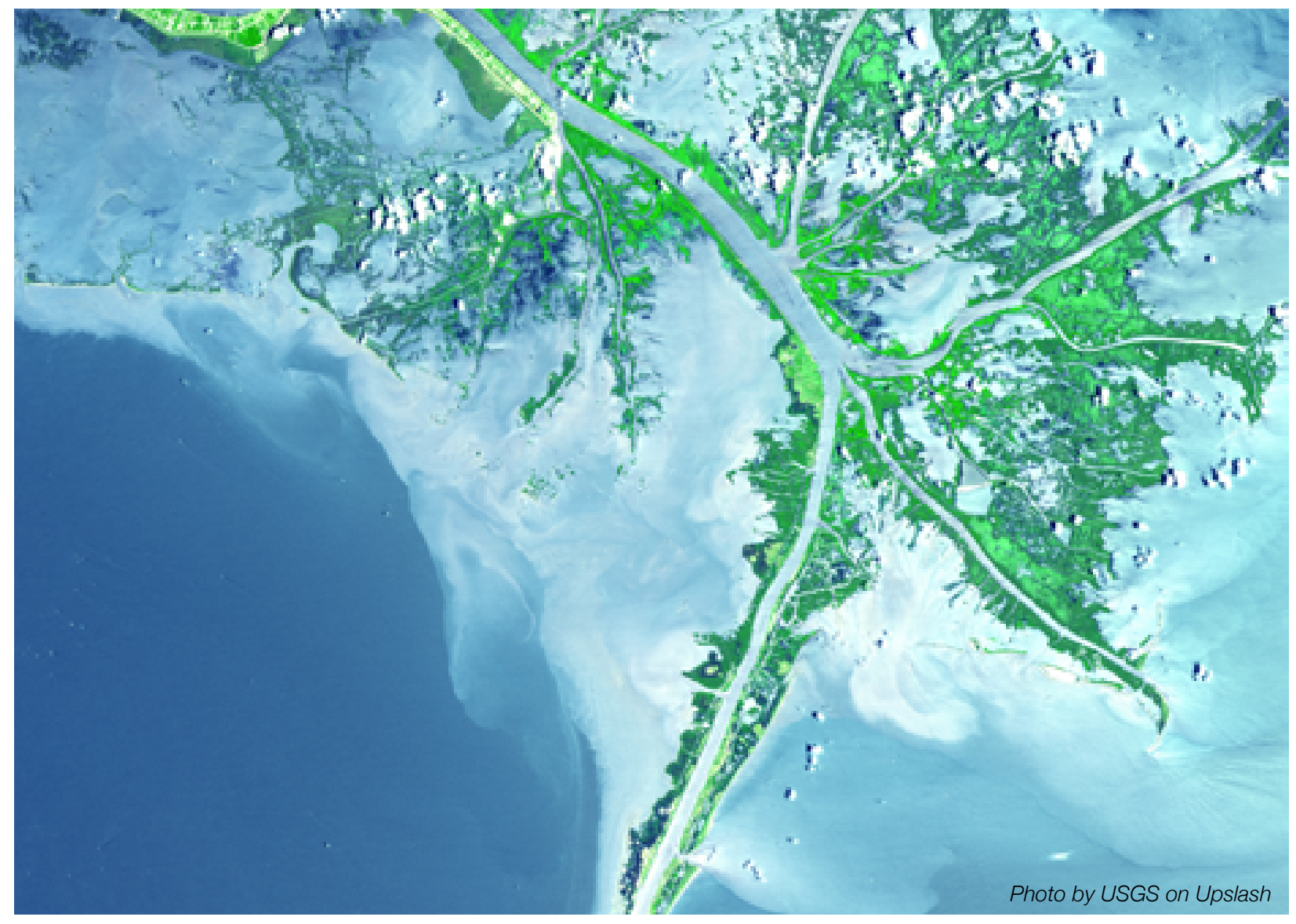




\section{c}

\section{THE PROCESS OF CREATING THE FRAMEWORK}

The creation of the Planetary Health Education Framework was commissioned by the Planetary Health Alliance (PHA). Based at the Harvard T.H. Chan School of Public Health, the $\mathrm{PHA}$ is a transdisciplinary network of thousands of individuals and $250+$ organizations from $50+$ countries working to understand and address the human health impacts of global environmental change. The PHA's mission is to promote, mobilize, and lead an inclusive, transdisciplinary field of Planetary Health and its diverse science, stories, solutions, and communities. To this end, the PHA is focused on facilitating and curating Planetary Health research, education, community-building and outreach, and action steps to achieve the Great Transition, a comprehensive shift in how human beings interact with each other and Nature.

The PHA community previously identified a gap in accessible frameworks that guide the delivery of Planetary Health Education. Thus, in July 2019, the PHA initiated the creation of the first Planetary Health Education Framework. As part of this process, the PHA convened an interdisciplinary, intergenerational, geographically diverse, and gender-inclusive task force by identifying prominent thought-leaders in the field of Planetary Health and/or education. The PHA invited their involvement in a 16-month process from December 2019 to April 2021. Seventeen individuals initially accepted the invitation to participate, and by the end of the process, the task force comprised 24 members (the authors of this document). The taskforce intended to build on the 12 cross-cutting principles for Planetary Health Education (Figure 1) to create a transdisciplinary (as used by Nicolescu, Morin \& de Freitas 1994) Planetary Health Education framework.

The timeline for creating the framework was broadly divided into five phases that took place between July 2019 and February 2021 (Figure 2). The first phase (July 2019 - December 2019) entailed a literature review and benchmarking process. The review of scientific and grey literature in search engines such as EBSCO, Google Scholar, OVID, and PubMed focused primarily on literature from ecology, complexity sciences, public health, veterinary medicine, engineering/systems, and global health education.

As part of the benchmarking process, academics engaged in ongoing education efforts, including courses, fellowships, and other educational programs related to Planetary Health. The Planetary Health Alliance's network of organizations and individuals, as well as its library of resources, provided a starting point for this phase of the process. 


\section{c}

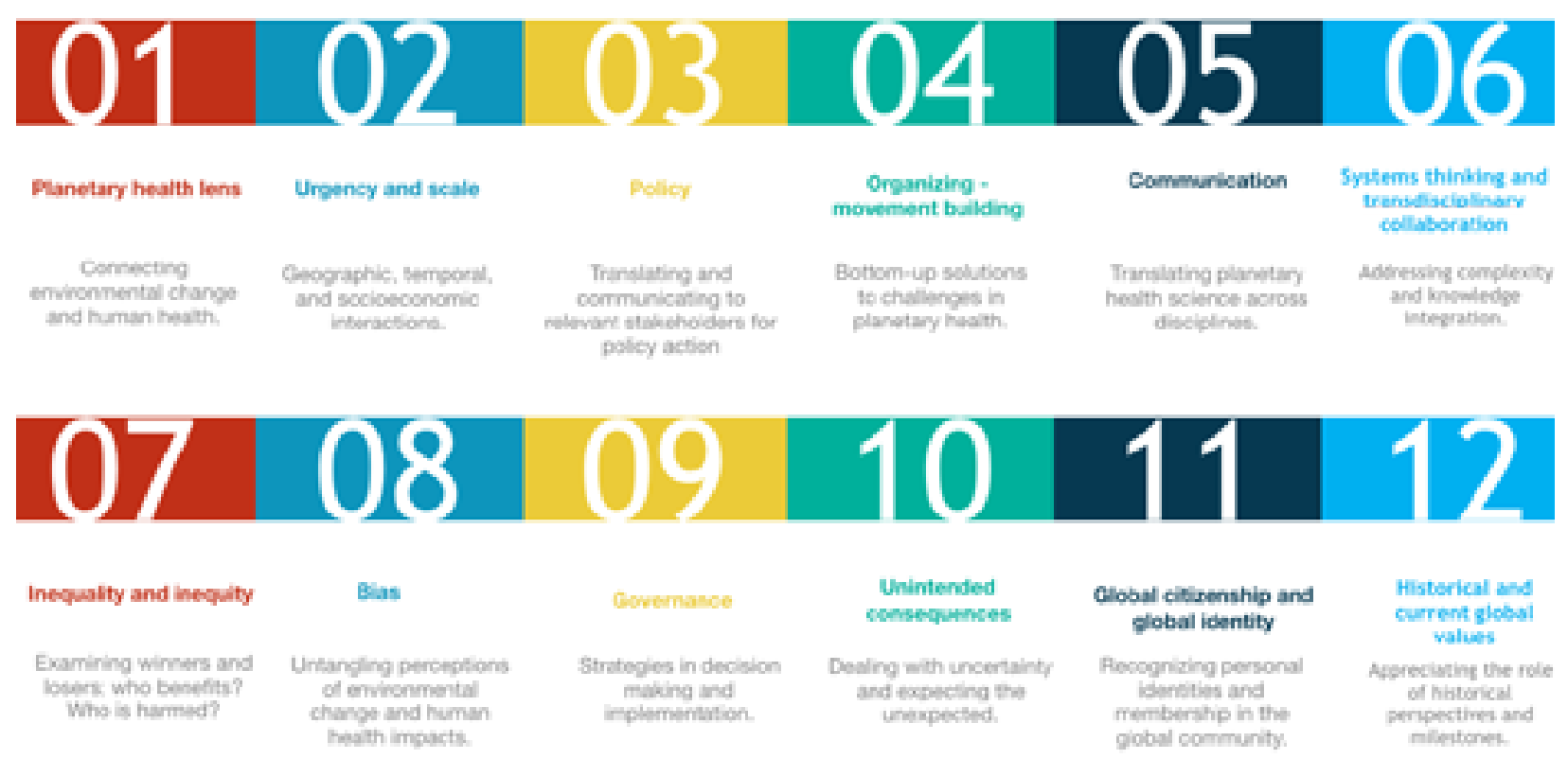

Figure 1. Cross-cutting principles for Planetary Health Education. Modified from Stone et al. 2018.

The second phase entailed a multi-stakeholder workshop at the Planetary Health Annual Conference in September 2019. This took place at Stanford University with attendees present in person (i.e., no remote participation). The workshop aimed to identify the current strengths and weaknesses in the profiles of learners currently graduating from higher education institutions through discussion informed by participants' experiences and the initial benchmarking process. A supplementary aim of the workshop was to collate participants' views on the key knowledge, skills, values, and attitudes necessary for those working in the field of Planetary Health.

During the third phase, from December 2019 to December 2020, the task force met monthly to advance the framework. Based on findings from phases 1 and 2, as well as through multiple online discussions, the task force developed a list of learning outcomes relevant to Planetary Health Education. Over 100 learning outcomes and competencies were collated and discussed among members of the task force. The statements were clustered into 12 domains through facilitated group discussions using consensus decision-making. Following this process, the number of relevant statements was reduced to 57 (see Annex 1). 


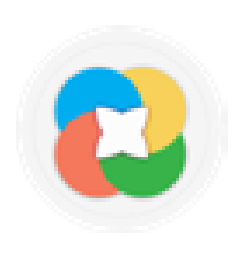

At this point, task force members recommended winnowing the framework to avoid covering a large set of topics but only at a superficial level, i.e., preventing a "mile wide, inch deep" approach. Through a consensus-seeking survey, domains and education outcomes were once again collapsed into five interrelated education domains through an inductive process (Figure 3). The larger task force broke down into five distinct groups (based on expertise, experience, and interest) to co-create the distinct domain descriptions included in this document. A shortlist of aspirational learning outcome statements were associated with each of the five domains as well as foundational literature.

The fourth phase, which took place from November 2020 and January 2021, engaged globally-diverse external volunteers to review and comment on the framework. The invited contributors included education scholars, experts on public health, global health, Planetary Health, one health, conservation medicine, ecohealth, ecology, and students from various fields. Involving both experts and students in this process was important to capture the perspectives of educators and learners. Each contributor provided written and oral feedback on the material compiled.

In the fifth and final phase (January-March 2021), the authors reviewed feedback from external reviewers and incorporated it into the framework.

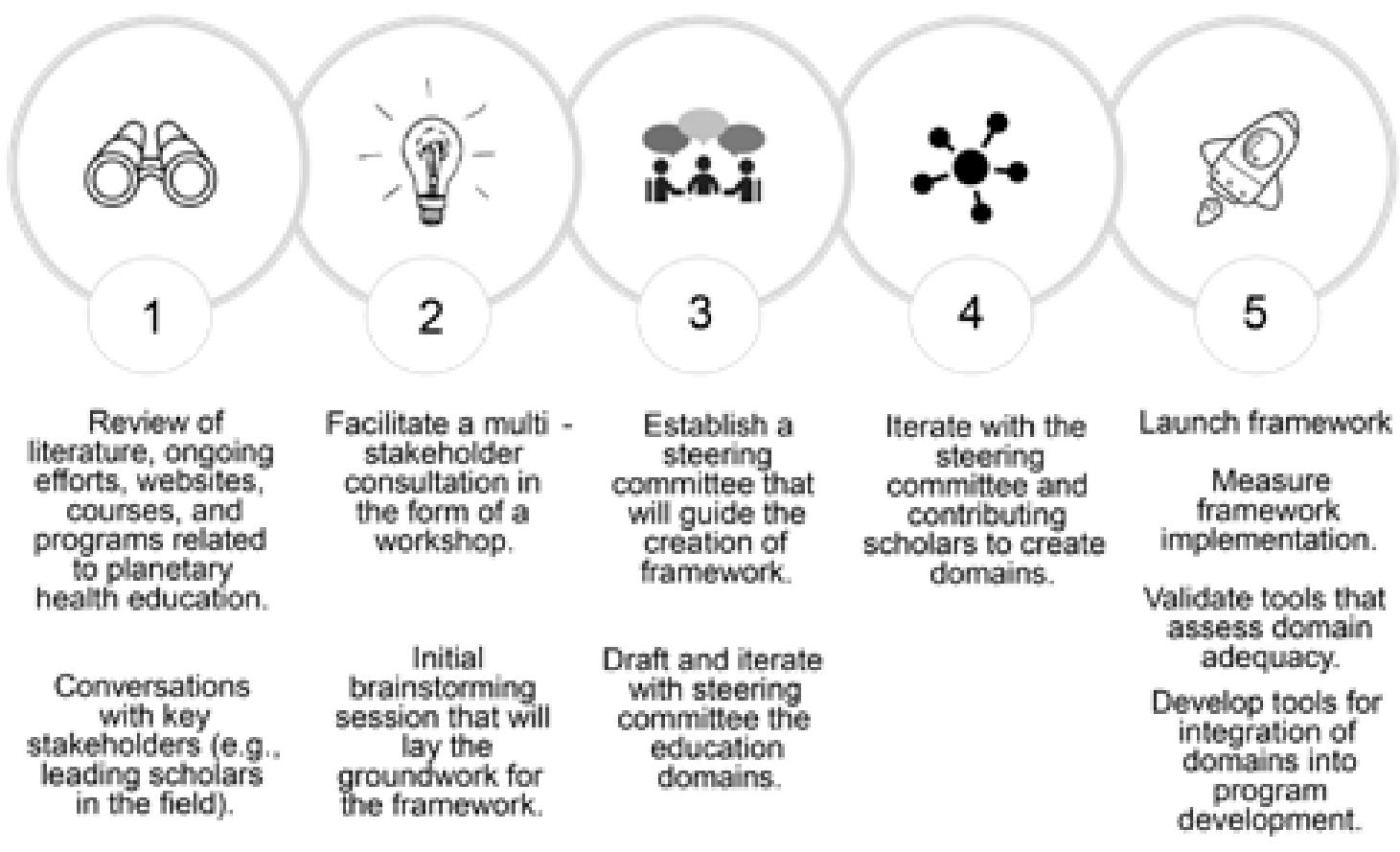

Figure 2. The 5-stage process of creating the Planetary Health Education Framework 


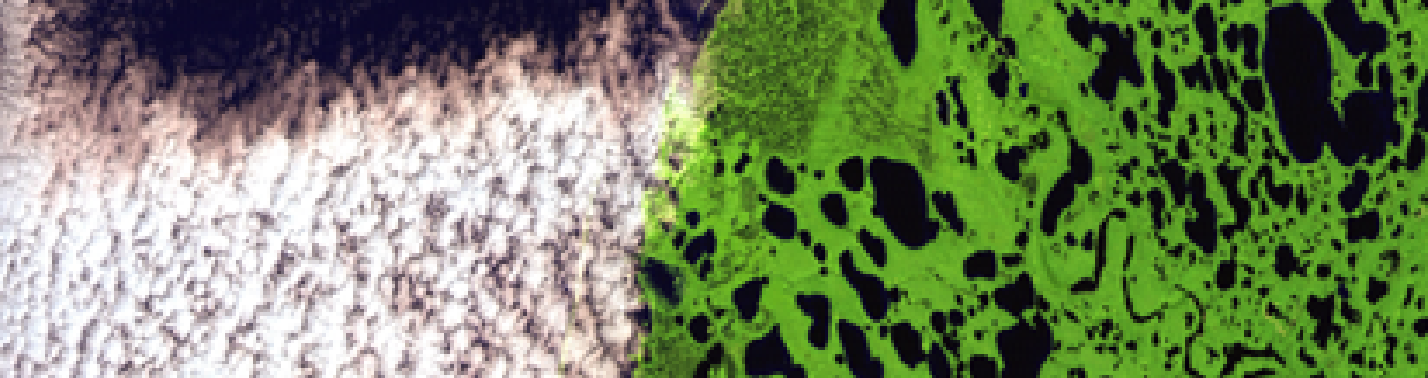

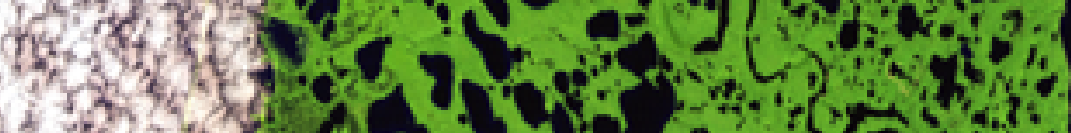

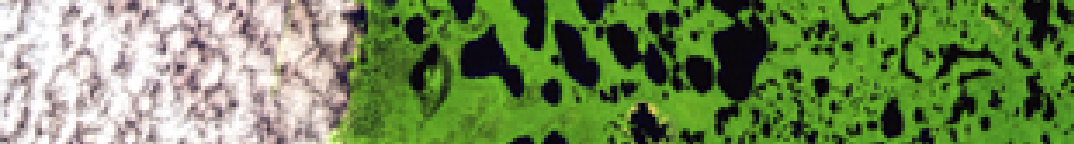

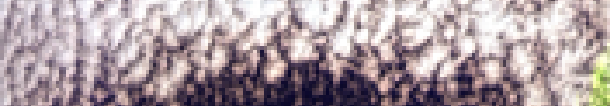
$\sin x$

Pon

\section{(ix}

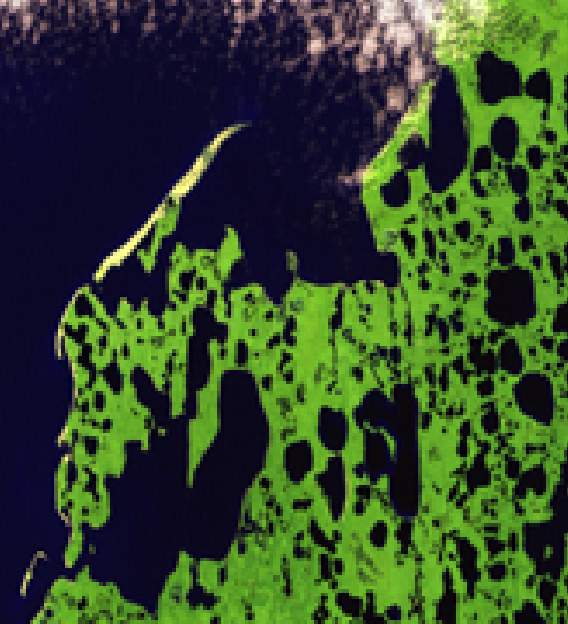

702

Gim

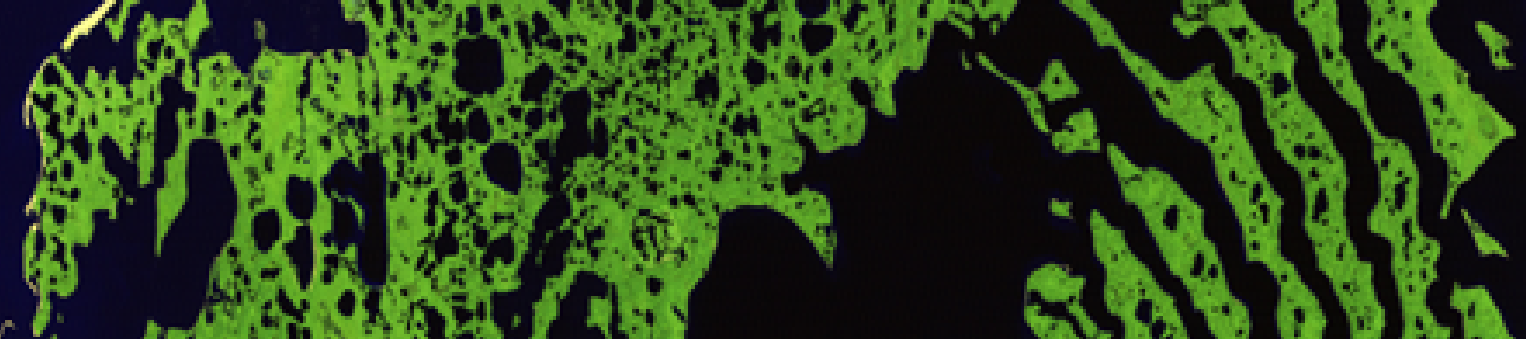

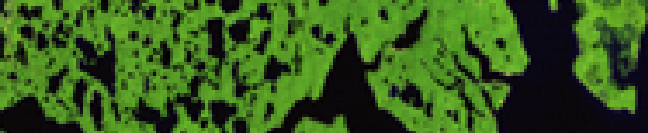
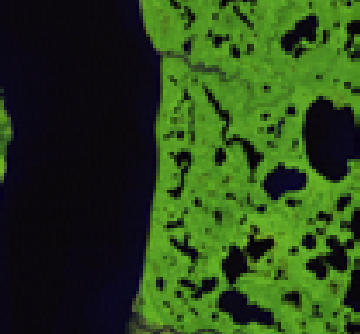
i. 7.

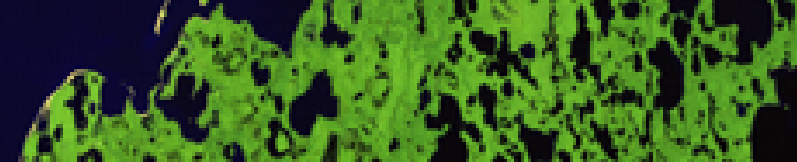

$60,260)=$ Anst r tons ar nos and

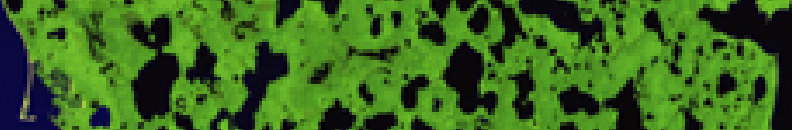
mitur ins inst

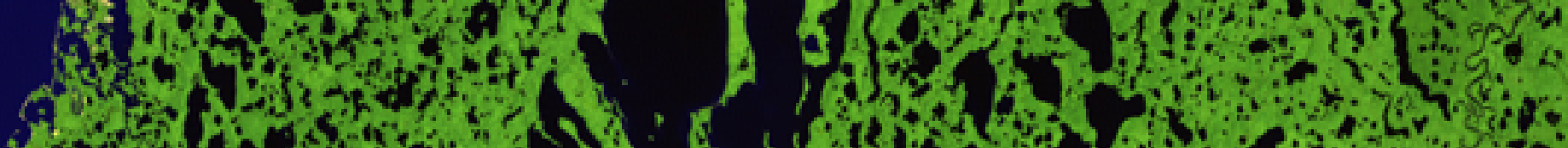

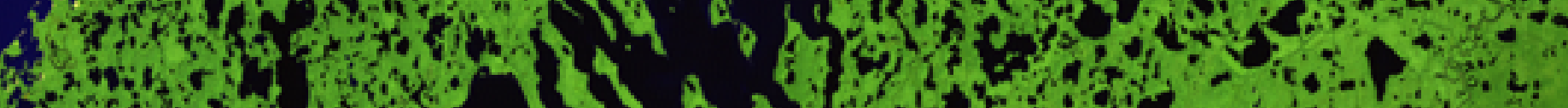
Shat 3.2.

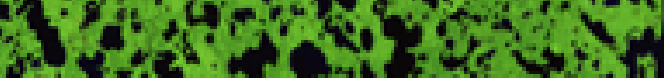

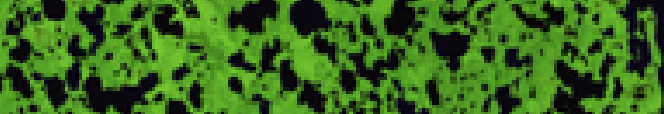

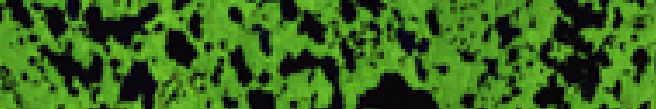

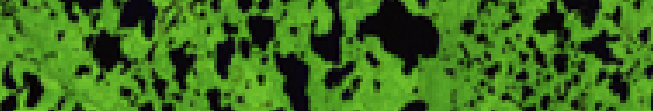

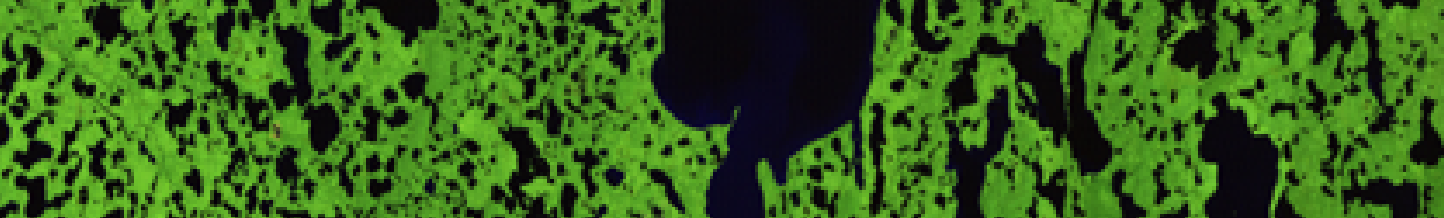
B.

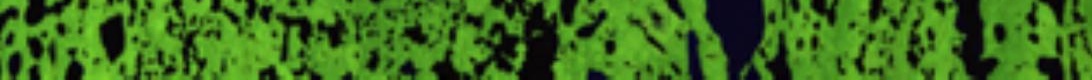




\section{c}

\section{THE PLANETARY HEALTH EDUCATION FRAMEWORK}

The Planetary Health Education framework considers five foundational domains that we as a group believe comprise the essence of Planetary Health knowledge, values, and practice (Figure 3): (1) interconnection within Nature; (2) the Anthropocene and health; (3) equity and social justice; (4) movement building and systems change; (5) systems thinking and complexity.

The framework can be understood as a common foundational language that serves as the cornerstone for diverse education strategies. To ground the framework in action, each domain includes suggested process outcomes and key Planetary Health themes and concepts. The work intends to move beyond thematic areas of interest or a prescriptive list of competencies towards the recognition of the diverse inquiries (i.e, the why/affective, the what/representation, the how/strategic) that can shape Planetary Health Education (Panel 1) (Meyer, Rose \& Gordon 2014).

\section{PANEL 1. DEFINING THE SCOPE OF THE FRAMEWORK}

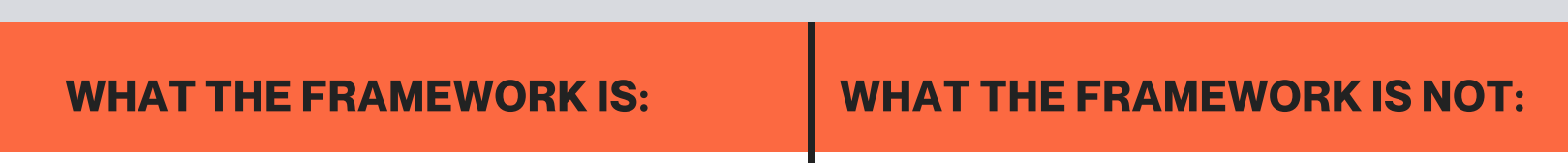

An organized yet dynamic interpretation, i.e., a model, of the breadth of Planetary Health education.

A common foundational language for learners and educators around the world.

A constructivist ${ }^{\triangleleft}$ proposal to achieve transformational learning ${ }^{\beta}$

A planning tool and approach for institutional, curriculum, and course design.

A recognition of diverse learning pathways.
A list of thematic areas.

A list of competencies, entrusted professional activities, or objectives to be achieved.

A prescriptive linear step-by-step learning process.

A definitive, static statement for Planetary Health education. 


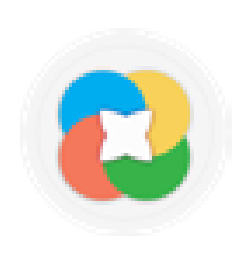

As a diverse working group, we, the task force, first needed to challenge our biases and assumptions as educators and practitioners to find commonalities. As a product of this process, we attempted to appreciate the diversity of schools of thought and theories that inform the learning process in different parts of the world. We strived to acknowledge the vastly different starting points and learning paths throughout the globe and internalize the non-linear nature of the learning process. Learning is full of iteration. It is always continuous, and in the case of Planetary Health, it often involves the process of unlearning - that is, deconstructing and uprooting long-held ideas, beliefs, values, and practices.

We also want to recognize that education frameworks are inherently shaped by the values of their creators. Whether these values are individualism, autonomy, employability, economic productivity, efficiency, or entrepreneurship. That is, what societies value undoubtedly shapes what learners should achieve in their education process. For the sake of transparency, the principal values that drove the creation of this framework are: inclusivity, diversity, humility, commitment, transgenerational and multispecies justice, equity, agency, autonomy, social cohesion, creativity, and partnership; all of which we consider instrumental for a successful Planetary Health learning process and subsequent collective action.

Because of the reasons mentioned above, this framework does not specify a stepwise learning process. It also does not map a list of competencies, objectives, or entrustable professional activities, which is typically standard practice in creating field-specific higher education frameworks. We further justify our approach by recognizing the dynamic nature of our current societal and environmental systems. Just like the learning process, knowledge and practice are not static. Theories, models, instruments, tools, and "real world" skills rapidly change in response to dynamic circumstances.

The framework aims to encourage life-long learning values and skills instead of seeking outcome objectives. The themes, topics, and concepts of this first iteration are based on the work of the Planetary Health Education Cross-Cutting Principles group and the subsequent work of the PHA Planetary Health Education Taskforce. As a working group, we further recognize the importance of providing tools towards the achievement of the UN Sustainable Development Goals (SDGs) Agenda 2030 and the Intergovernmental Science-Policy Platform on Biodiversity and Ecosystem Services (IPBES). 


\section{c}

We foresee that this approach will enable praxis (see Freire 2018), unique learning pathways, and educational outcomes that respond to environmental and social contexts, technologies, and resources available in varied learning settings. The framework is a constructivist proposal to achieve transformational learning through collaborative learning approaches. It is an attempt to step away from the predetermined and technocratic "standardized academic curricula" approach. The framework follows the reasoning that not all learners will achieve or will want to achieve the same level of mastery and that the learning process will depend on the future learner's context. The framework also provides the opportunity to adapt the learning path in a way that reflects stakeholders' (e.g., students, communities, educators) priorities and inputs, favoring participatory teaching methodologies (see outer circles of Figure 3).

In fact, the framework is set up to assist the educational design process. It can facilitate the creation of a diverse spectrum of educational programs and learning resources in the practice of Planetary Health. The framework should be relevant not just for specialists but also for higher education learners and even more broadly for learners of all levels. However, we chose to target higher education institutions for their unique positioning within societies worldwide, including as respected sources of innovation, thought leadership, and critical stakeholdership in extensive development efforts.

Finally, we recognize that there is still no final consensus on some of the terminology used in our framework. We acknowledge that this framework is neither exhaustive nor definitive. However, there is urgency to move forward. Therefore, the framework provides a starting point for anyone looking to incorporate Planetary Health into higher education programs in any discipline.

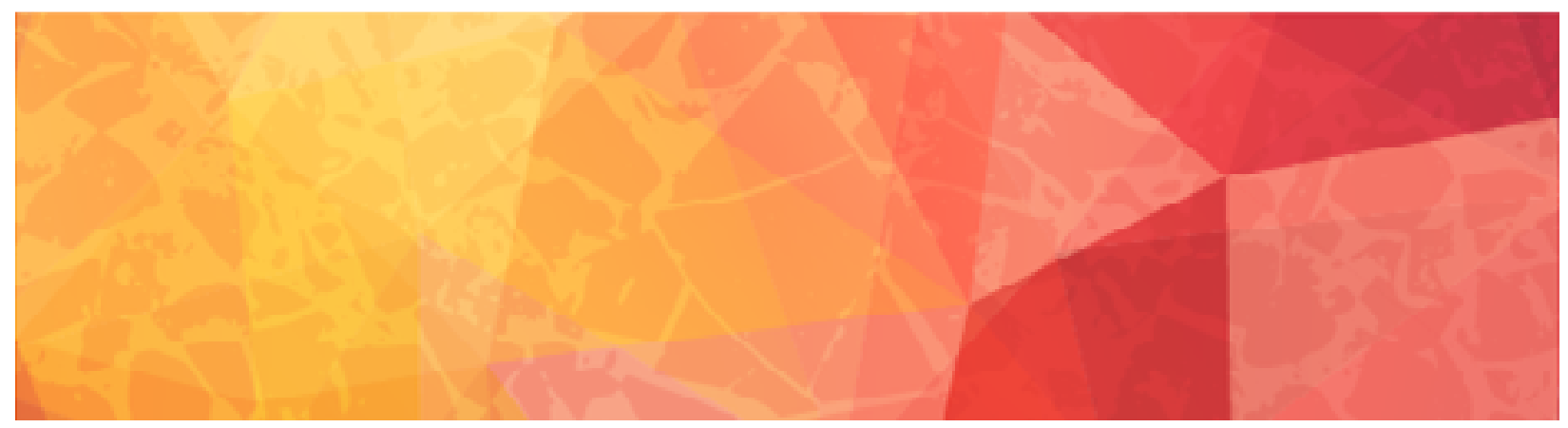




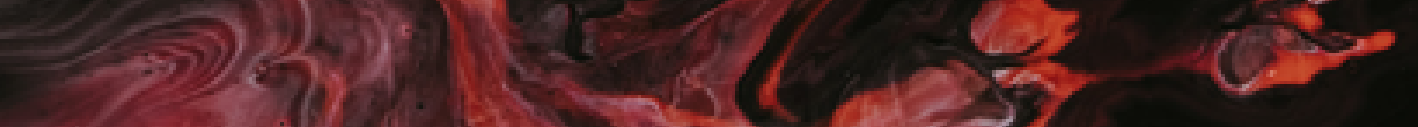

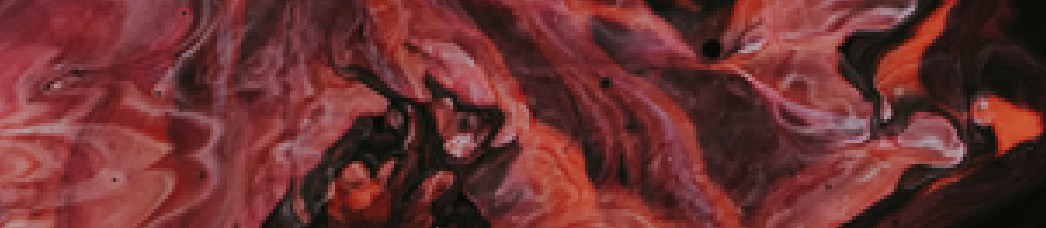

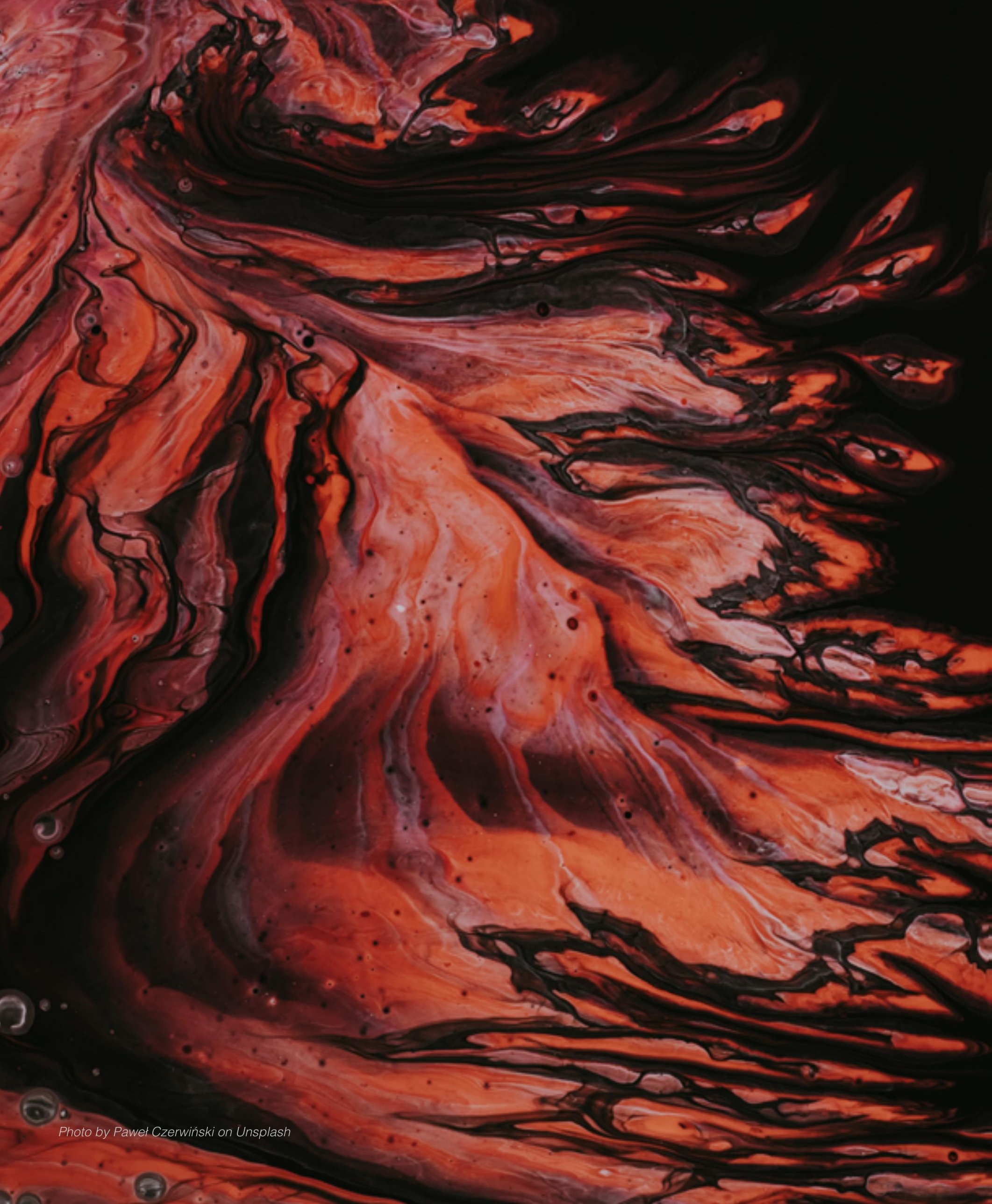




\section{c}

\section{THE FRAMEWORK DESIGN}

At the core of the framework are the five Planetary Health Education domains represented in an intertwined figure, similar to the threads of a rope (Figures 3 and 4). Although the model separates each domain, the reality of Planetary Health demands us to understand the interdependent and interconnected nature of each domain. The division of the domains is artificial and remains only for didactic purposes. While the domains can be teased out one by one (Figure 4), they only function appropriately when interwoven together. The analogy also emphasizes that the total strength of the framework, similar to a rope and its threads, is larger than the sum of its parts. The outer rings of the framework are the different conditions influencing the way in which the five domains are understood and taught; that is, how key Planetary Health themes, topics, and concepts will vary with time and context.

Fostering empathy for our planet through the recognition of the personal, cognitive, social, and emotional aspects of the education process is the central element of the Planetary Health Framework. In order for education to be truly transformative, it must be centered on the affective, experiential, and caring aspects of the learning process. As a commitment to this shift in the role of education from the informative to the transformative, we have placed the Interconnection within Nature as the central element of the five domains.

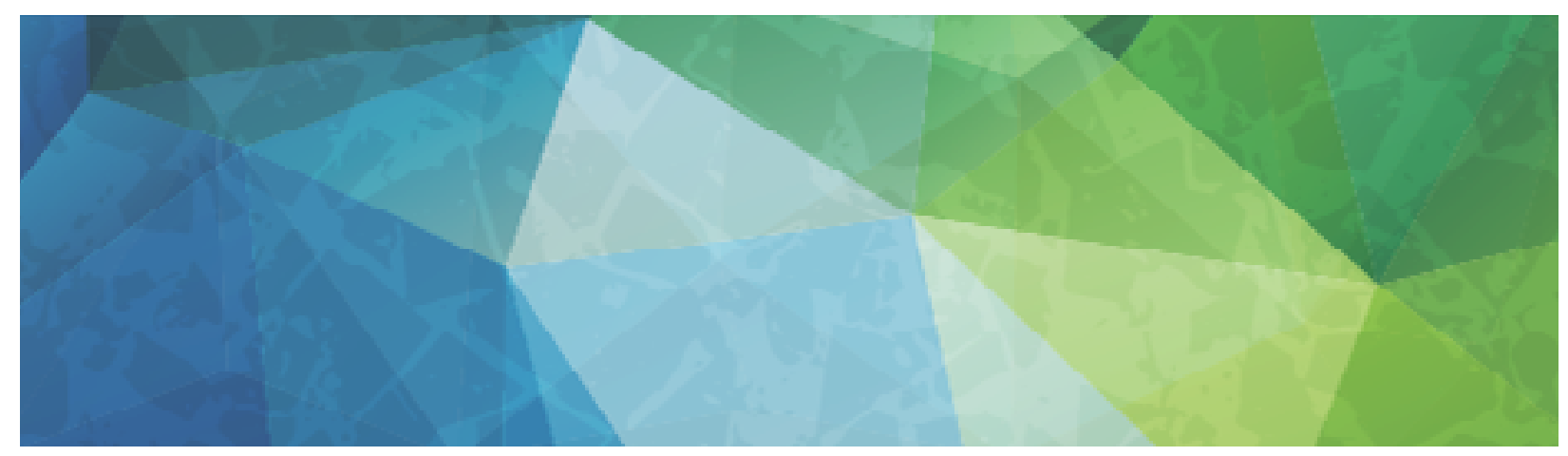




\section{c}

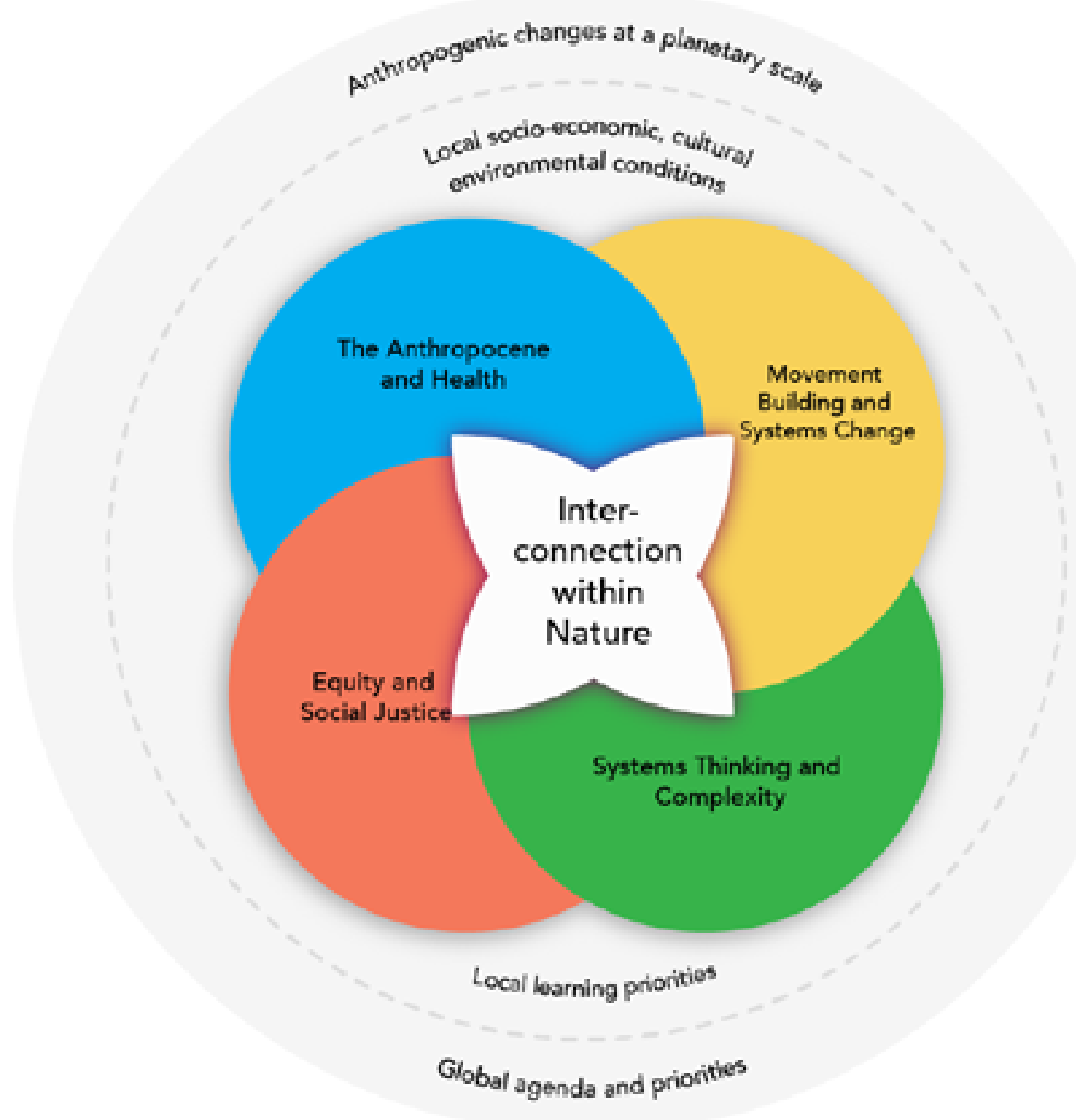

Figure 3. The Planetary Health Education Framework.
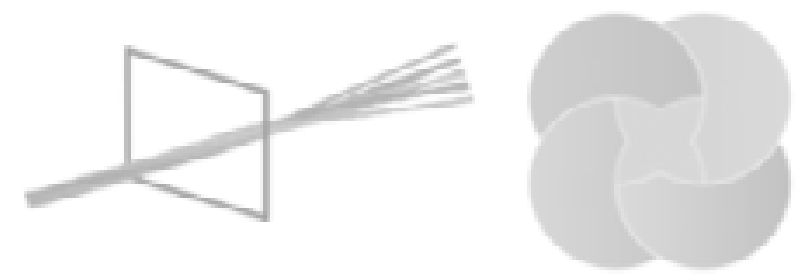

Figure 4. A transversal cut of a 5-thread rope. 


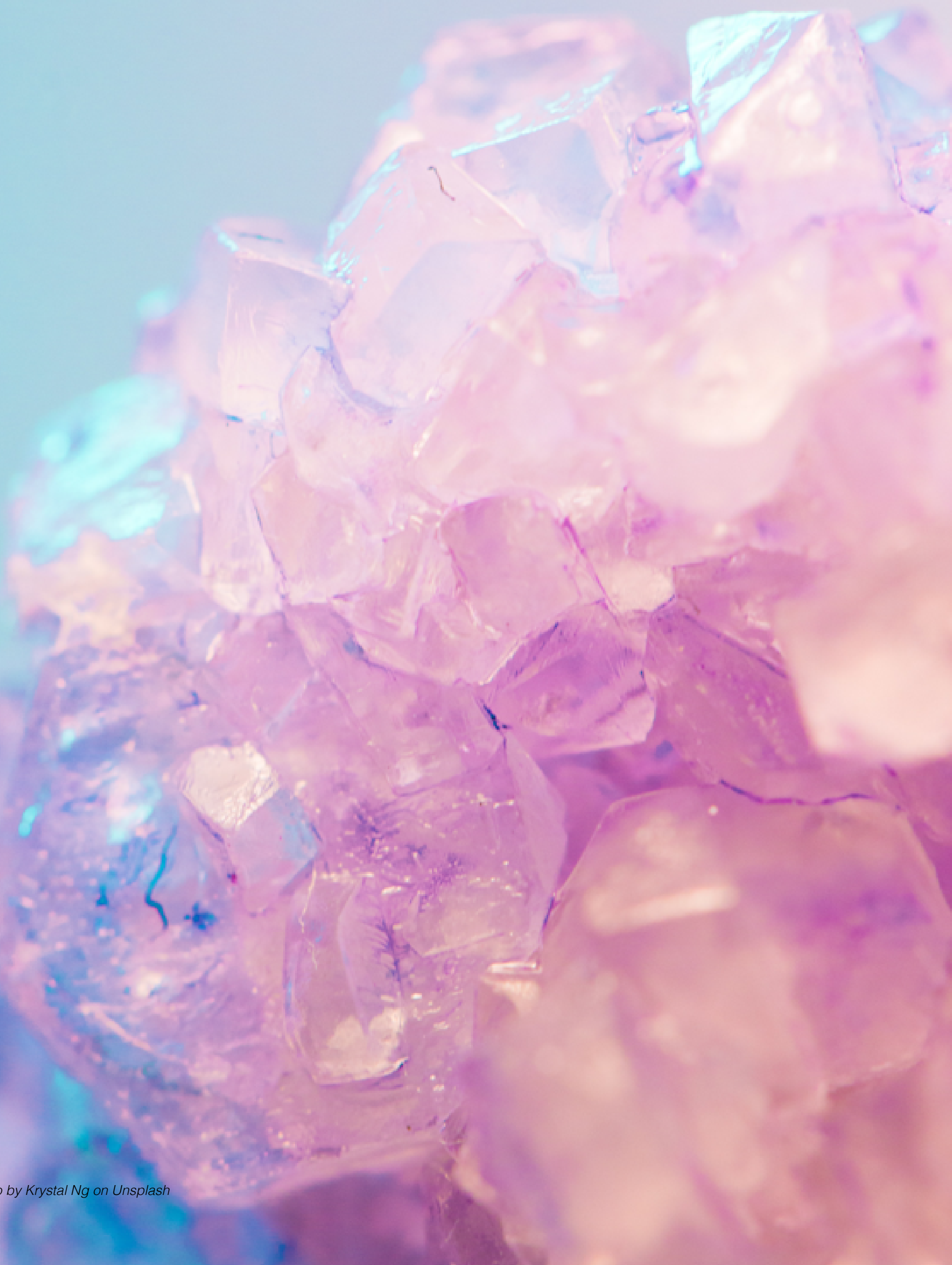




\section{c}

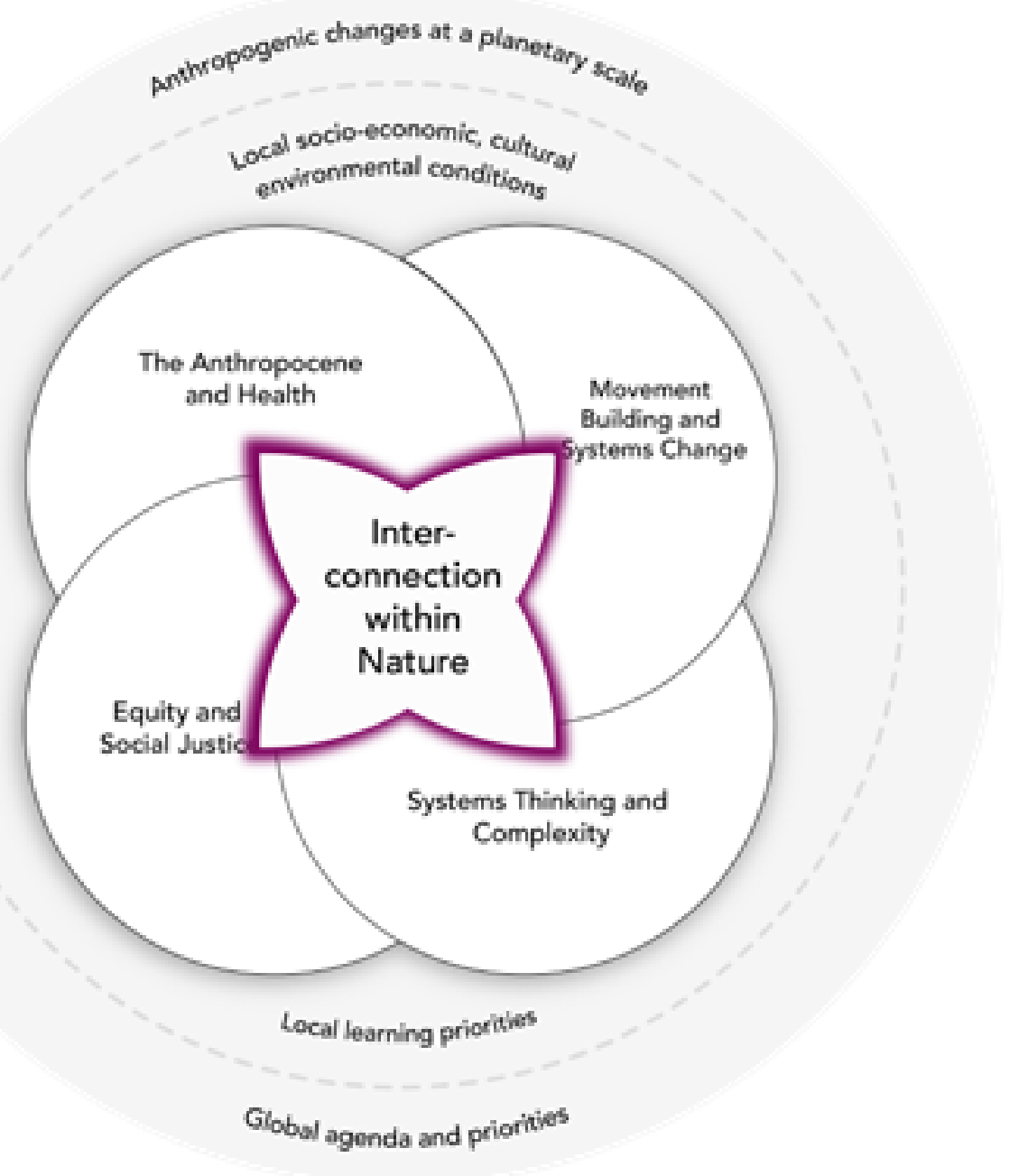




\title{
c
}

DOMAIN - INTERCONNECTION WITHIN NATURE

\author{
"In the vision for a healthy future, it is important to create the conditions that \\ enable the overcoming of the dissonance between 'being in nature' (i.e., nature \\ that surrounds us) and 'being of nature' (i.e., nature that embodies us)." \\ - Redvers et al. 2020 \\ "The First Law of Ecology is that "everything is connected to \\ everything." \\ -Bary Commoner
}

Understanding our role within Nature as a species and as individuals is foundational in Planetary Health science and practice. However, the understanding of interconnection within Nature has been a historically marginalized and ignored concept. This is why we understand it is a central and urgent task of education institutions to re-imagine our relationship within Nature.

To begin this framework, we must first reflect on why our civilization continues to overexploit Nature at an accelerated pace. Despite mounting evidence of our interdependence with the biosphere, our civilization's perspectives and consequential attitudes have not evolved accordingly. We proceed to over-extract natural resources despite the scientific consensus that this behavior is unsustainable. Further, academic institutions continue to neglect the importance of understanding and improving our relationship with Nature. This attitude is, in part, a symptom of a larger syndrome in which we suffer from an inability to recognize our interdependence on thriving and healthy ecosystems. This notion finds resonance in a recent initiative entitled The Thousand Names of Gaia, in which leading scholars discuss worldviews that would lead to a more harmonious and compassionate attitude towards Earth.

There are a multitude of explanations for our disconnection with Nature. The forced arrival of Eurocentric paradigms introduced a way of knowing that included domination and exploitation of Nature; Cartesianism, a dualistic view of the world, led to methodological reductionism, a historical hallmark of Western science. Cartesianism proposes that humans can be objective observers of reducible parts of natural systems. This reductionist paradigm has arguably led to many advances in human health in certain spheres. However, holism and notions of interconnectedness have frequently been a casualty of this approach. In addition to Cartesianism, rapid urbanization, alienation from food sources, colonial and domination mindsets, understanding progress as financial capital gain, the idea of ownership of "natural capital," predominant individualism, viewing Nature as an adversary, toxic gender dynamics (i.e., toxic masculinities), and sensory overload and desensitisation have further exacerbated our divide from Nature (Zylstra et al. 2014). 


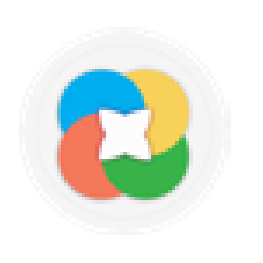

These aforementioned drivers explain, at least partially, why some societies view themselves as independent from -- not dependent within -- Nature. This false separation between humans and Nature perpetuates a deceptive culture of domination over Nature, inducing many current environmental crises. When humans think and behave as if they are separate from Nature, either as passive observers or active participants in the conscious or unconscious domination of natural systems, the result can be the life-threatening disruption of planetary boundaries. We are, in fact, experiencing many of these disturbances today, including climate change, the sixth mass extinction, deforestation, ocean acidification, and emerging infectious diseases to name a few. To survive, humans must shift the mindset and shared narrative from separation, apathy, and domination to interconnection, empathy, and partnership.

The Interconnection Within Nature (IWN) Domain is centered in a continuation of similar frameworks described in the field of ecopsychology, environmental education, and related sustainability sciences, including, for example, "human-nature connectedness", "nature connectedness" "nature connection" "connectedness with nature", "connection to nature", or "nature relatedness" (Zylstra et al. 2014). This approach is simultaneously informed by worldviews, knowledge systems, and traditions of Indigenous Peoples and other cultures that still maintain their sense of interconnection within all Nature. In this domain, we refer to "interconnection" as an indicator for mutualism, reciprocity, and symbiosis. We use the term "within" to denote that humans are part of and not separate from Nature. Finally, we define the word "Nature" as encapsulating Earth and life (including humans).

We believe that bridging ways of knowing respectfully and with direct partnership and proper ethical engagement will better enable an emergence of co-benefits for individuals, communities, and our planet. This includes the consideration of Indigenous and Western knowledge paradigms, as opposed to Indigenous vs. Western systems of knowing, in education and practice (Redvers et al. 2020). Thus, the IWN domain recognizes diverse knowledge and spiritual traditions, especially those of Indigenous Peoples (Box 1), which embody the deep interconnection of humans within Nature.

In realizing the bond between humans and Nature, we wish to foster a new ethos that supports resilient and vibrant socio-ecological systems. An IWN approach addresses the cognitive (sense of connection), the affective (caring component), and the behavioral (commitment to act). IWN reaches beyond the simple knowledge transmission of social-ecological interactions traditionally offered at educational institutions and hopes to surpass superficial and short-term attempts to "reconnect" or "spend time" in Nature. It is not just contact with nature but the nature of the contact that matters most. 


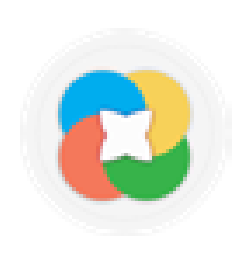

IWN demands that the cognitive, affective, behavioral, and spiritual, if appropriate, are incorporated when designing educational strategies (Zylstra et al 2014). Although there is still a gap in the understanding of which education strategies most effectively work towards "reconnecting" with Nature, examples abound (see for example, Table 3 in Zylstra et al. 2014)

We further acknowledge that there are many ways to shift our cultural narrative towards a more comprehensive understanding of IWN. Instrumental in this transition is Mi'kmaq Elder Albert Marshall's concept of "Two-Eyed Seeing." This term describes the benefit of respecting and relying on multiple perspectives (Bartlett et al 2012). In other parts of the world, it has been referred to as the "Two-Ways" or "Both Ways" approach. For example, the Yolnu people of northeast Arnhem Land, Australia, use the word "Ganma"-the place where freshwater and saltwater meet and mix - to refer to the blending of parallel systems of Western and Indigenous knowledges (Muller 2012; Verschuuren et al. 2015).

Our appreciation for IWN is crucial for Planetary Health education as studies increasingly demonstrate that time spent within Nature makes humans healthier. In fact, studies have found that being within Nature strengthens our immune system, reduces depression, elevates mood, lowers stress, improves overall psychological resilience and mental wellbeing, and positively influences life-expectancy (Kuo, 2015). Whether the end result of IWN strategies is called "pro-environmental behavior," "pro-Nature behaviour," "environmentally responsible behavior," "conservation behavior," "ecological behavior," or "sustainable behavior" (Zylstra et al. 2014), IWN can begin to build ways of life that affirm and promote the full flourishing of Earth's natural systems.

This IWN domain calls on educators to expand the content of higher education so that it includes Indigenous voices and presence, as well as other non-dualistic cultural, philosophical, spiritual, and scientific traditions that center the integration of humans within Nature. We acknowledge that incorporating IWN within education institutions will only address our disconnect from Nature in a partial manner. In regenerating the human-nature relationship, education institutions also need to personify the change we want to see in learners (e.g., divesting from fossil fuels). Today, there is no single path to reach and cultivate IWN. Awareness and practice of IWN will be a lifelong process unique to every individual and every context. A deep awareness of belonging to Nature may encourage students and professionals to pledge to protect Planetary Health. As a human species, we will need everyone to acknowledge the innate interconnection that exists within Nature to promote the partnerships needed to create a healthy future for all. 


\section{C}

\section{Box 1. Indigenous Knowledge and Interconnection Within}

One of the cross-cutting principles of Planetary Health Education states:

"An understanding of the past is necessary to solve the problems of the present. To grasp the necessity and urgency of Planetary Health, students need to be aware of the historical perspectives and milestones that have laid the foundation for the field,

including those perspectives that have been historically marginalized or ignored" (Stone et al. 2018, pg. 193).

There are additional ways in which we can understand the relationship between humans and Nature. These ways of knowing point toward interconnection within Nature. For example, from Indigenous Peoples, the original observers and protectors of ecosystems, we can respectfully learn behaviors that affirm and promote the full flourishing of Earth's natural systems.

For millennia, Indigenous Peoples of diverse locales have developed paradigms based on direct experience and participation with Nature rooted within the understanding of interconnection. Indigenous Peoples' experiences, observations, and laws of existence surrounding the notion of interconnection are reflected in their customs, values, dance, music, the arts, traditional medicine, and expressions of spirituality, while also being actioned through their active stewardship of our natural world.

As Harmin et al. (2017) found, being open to Indigenous perspectives allows educators, scholars, and students to gain understanding and appreciation of their interconnection and relationships within Nature.

"For Indigenous people there is a recognition that many unseen forces are at play in the elements of the universe and that very little is naturally linear or occurs in a two-dimensional grid or a three-dimensional cubic form. Indigenous people are familiar with the notions of energy conservation, irregularities in patterns and anomalies of form and force. Through long observation they have become specialists in understanding the interconnectedness and holism of our place in the universe" (Barnhardt \& Kawagley 2005. pg. 12). 


\section{c}

Other key features of Indigenous Traditional Knowledge Systems (TKS) include elements of reciprocity, relationality, responsibility, holism, and the absolute inseparability of the sacred and secular. Learning is land- or place-based, experiential, spiritual, and intergenerational (Antoine et al. 20I8). A significantly influential TKS in Latin America, "Buen Vivir" or "Sumak Kawsay" (in Quechua), is a sacred cosmovision partially included in the constitution of Ecuador in 2008. It recognizes intrinsic rights of Nature or "PachaMama," and may serve as inspiration for other countries as well (e.g. the recent granting of "legal personhood" to the rivers Whanganui in New Zealand and Ganges in India).

As an example of the integration of Western and Indigenous knowledge systems, we can apply the concept of "Two-Eyed Seeing" (see in-text description) by looking through one eye. Through this lens, we can learn to appreciate the research findings that demonstrate the fact that we cannot just rely on the visual experience of Nature, but instead need to deepen our forms of interaction within Nature in order to make relationships more immersive and meaningful (Otto \& Pensini 2017). We can learn how to deepen our kincentric experience through the practice of interconnection, which may allow for more holistic, place-based, spiritual, and intergenerational relationships. In the words of Elder Albert Marshall, "No one being is greater than the next...we are part and parcel of the whole, we are equal, and that each one of us has a responsibility to the balance of the system" (Bartlett et al. 2012, pg. 332). Perhaps, this dialogue between complementary cultures can be informed by the new paradigm of Gaia, where a human-environment relationship so intuitive to Indigenous wisdom is articulated in the language of Western science.

The terms "kincentric ecology" and "kincentricity" with the natural world are other terms of particular significance to understand IWN and were created by Indigenous scholars to translate concepts of interconnection into the English language (Martinez 2008; Salmon 2000). Where Anthropocentricity harkens to significant exploitation and extractive industries, kincentricity is the relationship that supports an obligation to renew the planet in harmony with all kin (Martinez 2008).

\section{Key concepts and areas of study Interconnection within Nature}

Traditional knowledge systems

Nature connectedness (human-nature connectedness)

Ecological identity

Epistemological diversity and humility

Worldviews: from Animism to Cartesianism

Two-eyed seeing

Kincentric

Resilience

Pachamama, Gaia, and other similar concepts 


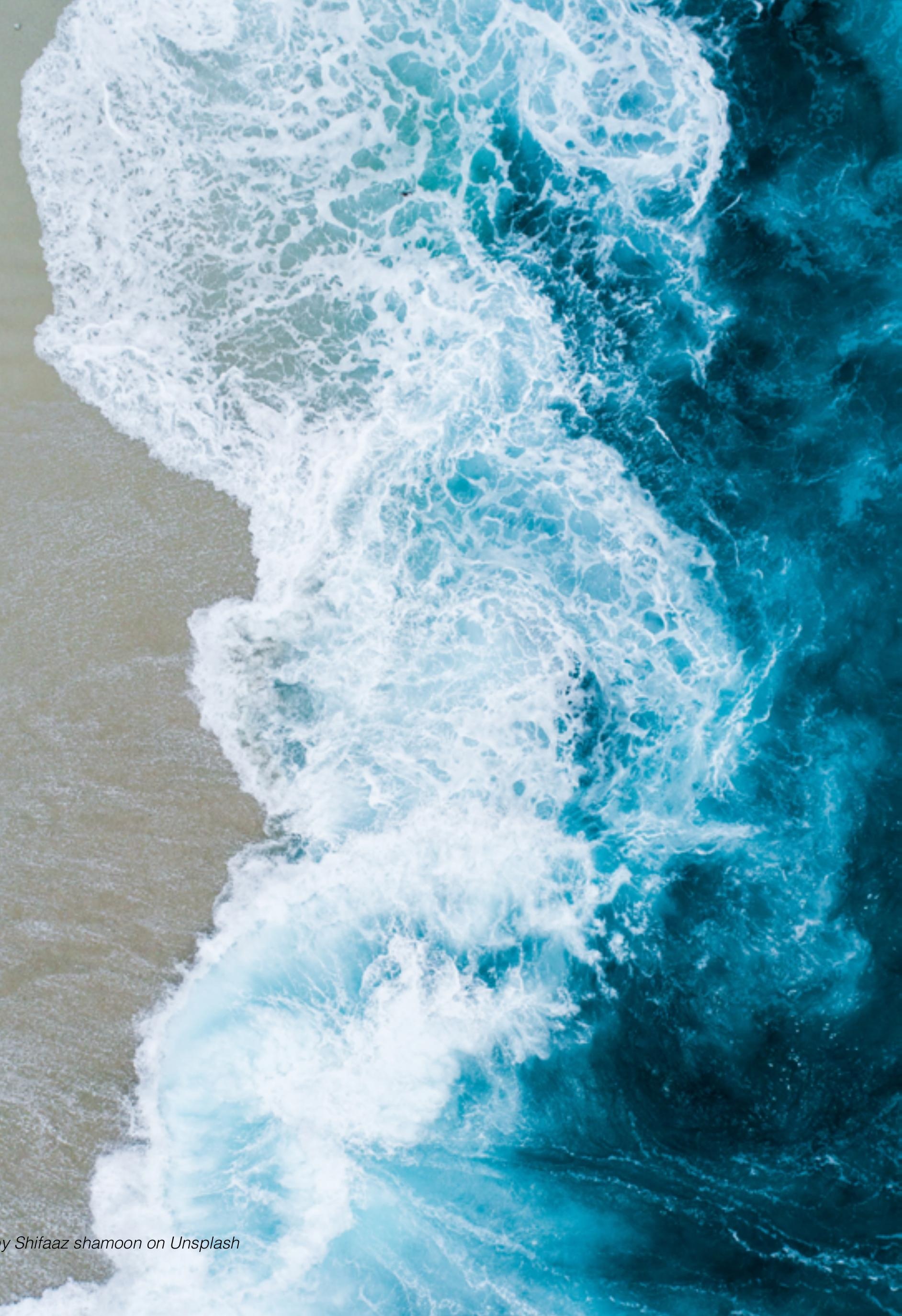




\section{c}
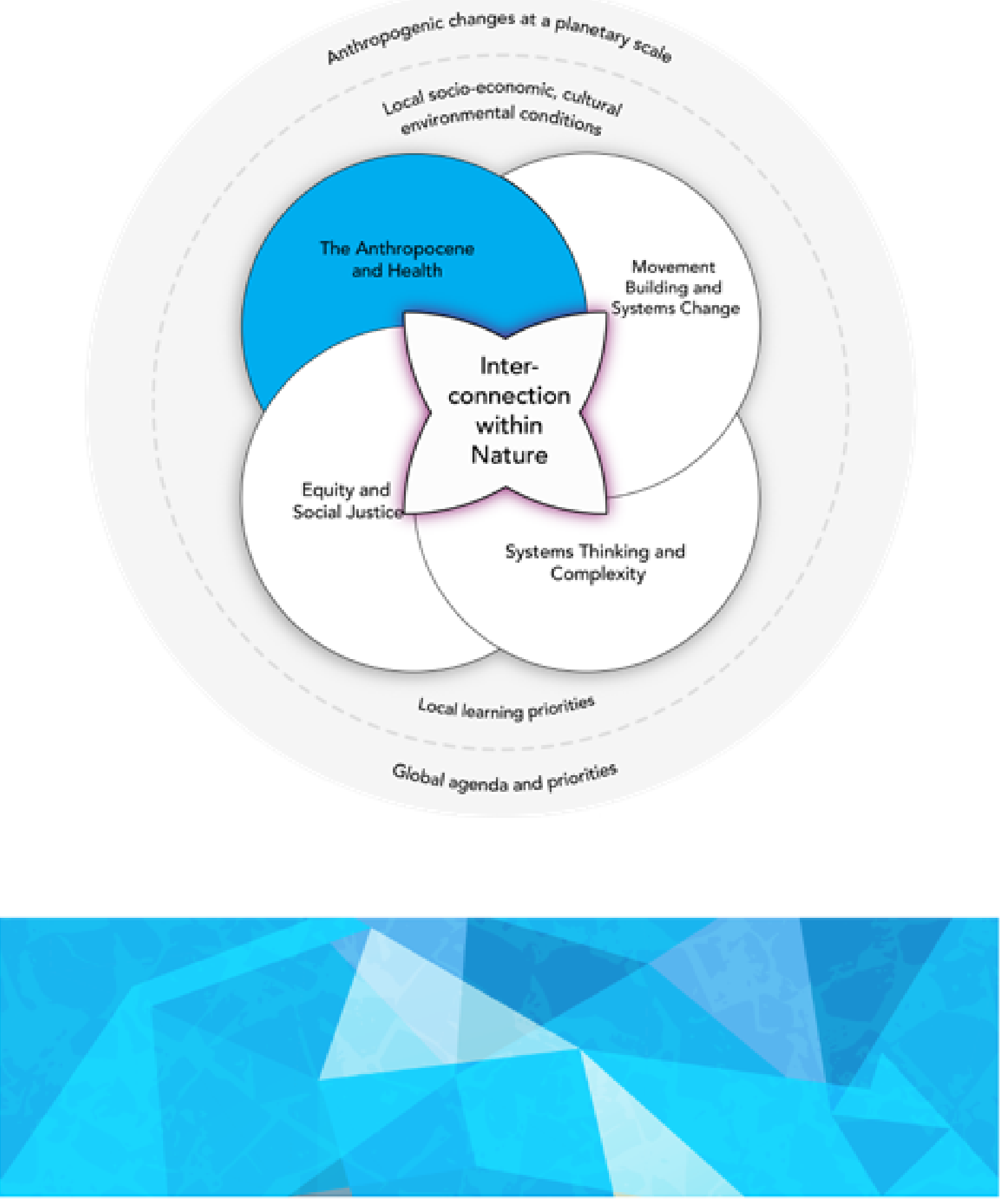


\title{
C
}

\section{DOMAIN- THE ANTHROPOCENE AND HEALTH}

\author{
"You cannot get through a single day without having an impact on the world around you. What \\ you do makes a difference and you have to decide what kind of a difference you want to \\ make." \\ "COVID-19 offers us the chance to change who we were and what we stood for. It would be \\ a shame to miss this opportunity for a second chance." \\ - Anthony T' Hincks, An Author of Life
}

The Anthropocene is about the Human Age. The term combines the Greek roots "anthropo-," meaning "human," with kainos or "-cene" the standard suffix for "epoch" in geologic time. Nobel laureate Paul J. Krutzen and Eugene Stoermer coined the word in an essay for an earth systems science journal (Steffen et al. 2015). The Anthropocene is a concept marking the start of a proposed geologic epoch in which the dominant force shaping Earth's biophysical conditions is human activity.

Currently, the Anthropocene is characterized by massive disruptions in earth system processes, climate stability, and ecosystems that have resulted from human activities' ballooning of humanity's ecological footprint. Putatively beginning in the last four hundred years, increasing impacts are associated with the "Great Acceleration," a global change after the second world war manifesting in a massive growth rate of human activities and changing demographics beginning around 1950 (Steffen et al. 2015). This epoch highlights the recognition of the blurred boundaries between humanity and Earth's systems, in which humans induce significant environmental changes that threaten the entire biosphere, including humans themselves (Revkin 2016).

Herein, the Anthropocene and Health Domain refers to the understanding of how specific anthropogenic impacts on Earth's natural systems are connected to health outcomes, using the social and environmental determinants of the health framework (e.g., policy, governance, gender, place of work, ethnicity, biodiversity, water, soil, and air quality, built environment). The domain promotes a social and ecological approach to health promotion and disease prevention, ranging from individual to population-level determinants of human, animal, and ecosystem health. The Anthropocene and Health Domain is also a recognition of the opportunities to achieve the Great Transition through human stewardship of Earth's natural systems (Díaz et al. 2019). Central to achieving improvements across species and ecosystems is moving beyond anthropocentric models of health and incorporating broader animal and ecosystem determinants of health frameworks (Card et al 2018). 


\section{c}

For learners, the cross-cutting goal within this domain is to appraise how anthropogenic changes to natural systems, including their proximal and distal causes, influence health outcomes. Understanding this goal requires a special focus on the interconnections between the following anthropogenic changes and health impacts (Table 1) (Myers \& Frumkin 2020; Whitmee 2015; Aguirre et al. 2012):

\section{TABLE 1. SELECTED ANTHROPOGENIC CHANGES AND THEIR MULTIDIMENSIONAL HEALTH IMPACTS}

\section{ANTHROPOGENIC CHANGES}

Biodiversity shifts

Land-use change

Change in biogeochemical flows

Global pollution

Climate change

Extreme weather conditions

Resource depletion (e.g., food and water)

\section{HEALTH IMPACTS}

Changing infectious disease patterns

Changing non-communicable disease patterns

Changing nutritional disease patterns

Changing mental health patterns

Changing reproductive health patterns

Shifts in nutrient density of food

The Great Transition will also require an understanding of the underlying and mediating factors that enhance or lessen these health impacts (Figure 5). In the previous domain, separation from Nature was emphasized as one of the most important causes of our current predicament. As such we suggest adding it to Figure 5 as an "underlying driver." In addition, a foundational change in the proposed value system has also led to circumstances in which hyper-consumption, dysfunctional economic models, and overt disregard for future generations are normalized. Societal and individual values ultimately shape the policies (or there lack of) and unjust power dynamics,e.g., current governance structures, that perpetuate our incursion on Earth. Therefore, it must be understood that mediating and underlying factors can be both "cause and consequence" by coexisting in the form of feedback loops. 


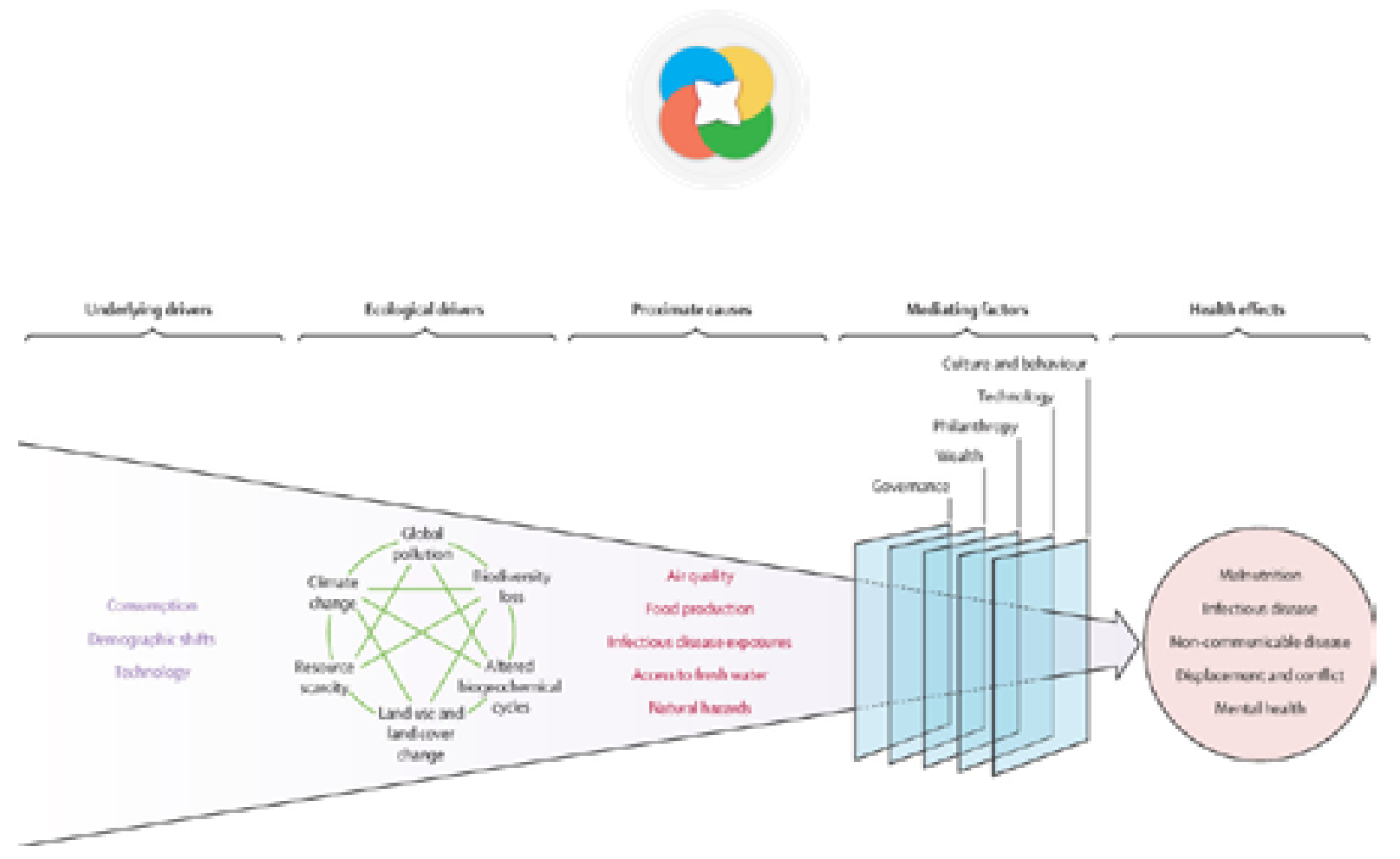

Figure 5. Schematic illustrating the impacts of anthropogenic change on human health (Myers 2017).

\section{Key concepts and areas of study The Anthropocene and Health}

The social and environmental determinants of health

The Anthropocene and related concepts (e.g., capitalocene)

Anthropocentric and ecocentric

Globalization

Demographic transition

Epidemiological transition

Planetary boundaries

Ecological footprint 


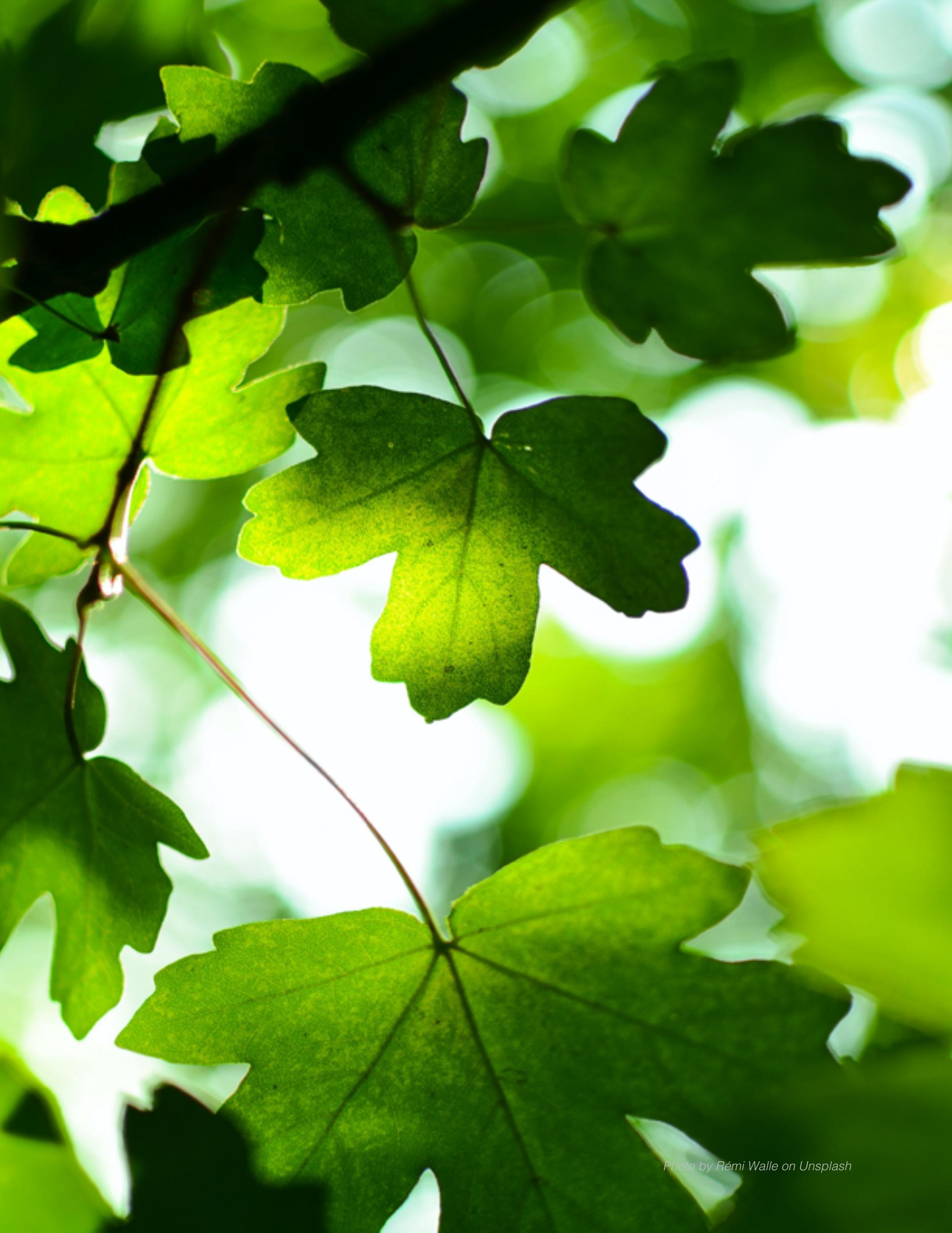




\section{c}

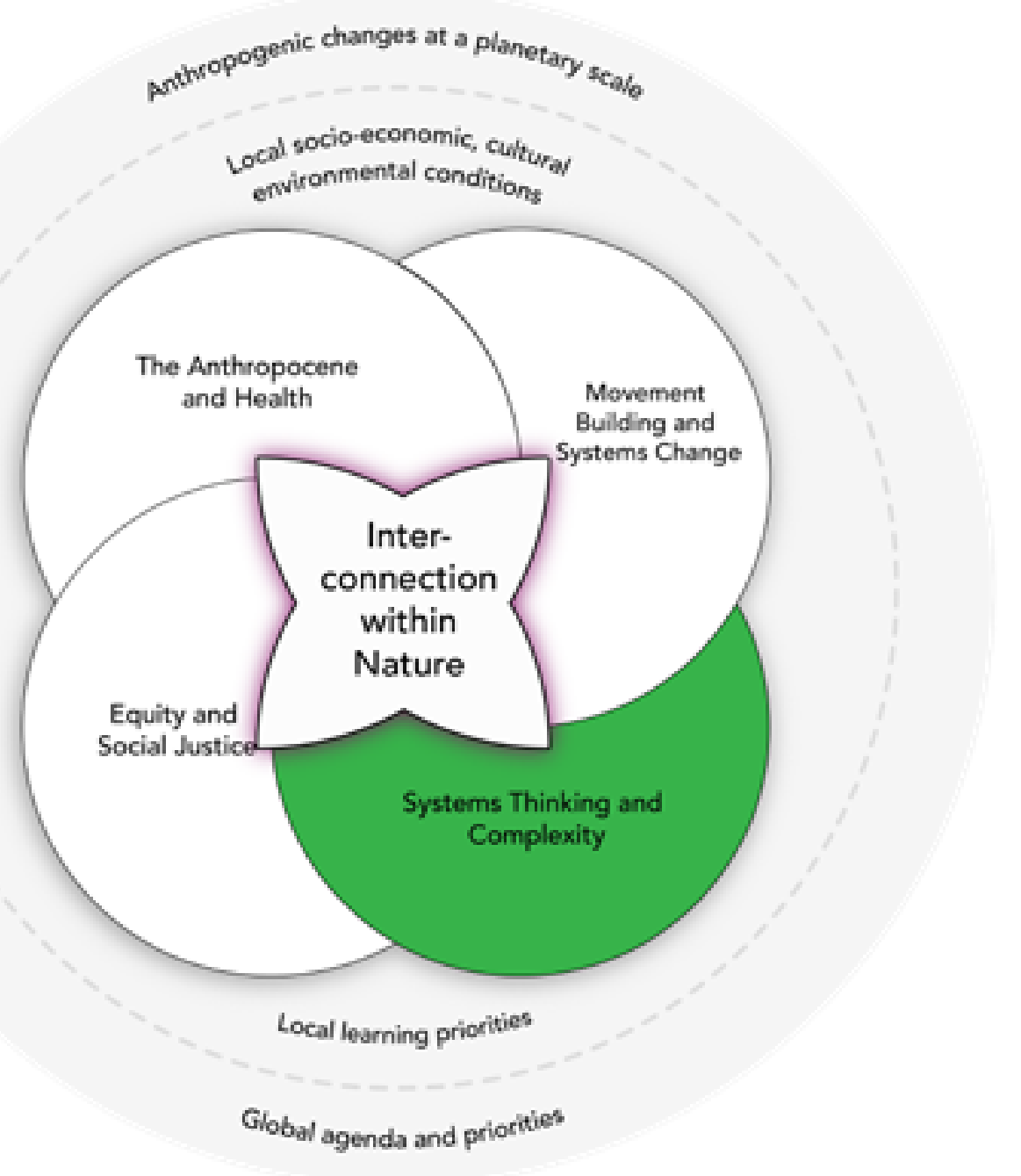




\section{C \\ DOMAIN-SYSTEMS THINKING / COMPLEXITY-BASED APPROACHES IN PLANETARY HEALTH}

"Therefore, it is not only our ignorance, but also our knowledge that blinds us." -E. Morin

"Leave your ego at home and learn to listen" -A.A. Aguirre

The word systems itself is derived from the Greek "sunistánai" meaning to 'stand together' (i.e., as a whole). The environmental scientist and lead author of the Club of Rome's 'Limits to Growth', Donella Meadows, defined systems as:

A set of elements or parts that is coherently organised and interconnected in a pattern or structure that produces a characteristic set of behaviours, often classified as its "function" or "purpose" (Meadows 2008)

Therefore, systems thinking aims to connect elements to each other within some notion of a whole entity. Systems thinking uses explicit models (clear assumptions) rather than mental implicit models (i.e., unrevealed assumptions and missing or lack of data points), thereby helping to identify and communicate underlying assumptions and provide a basisv for models to be reproduced by others. Systems thinking has origins and applications in many different fields and theories, i.e. Panarchy (Wilcox et al. 2019). In essence, it requires a transdisciplinary approach to conceptualize, model, and understand complex phenomena in search of beneficial changes.

However, in higher education, reductionist tendencies that overlook the complexity of systems thinking still prevail. This is most clearly represented in the siloed nature of traditional disciplines and trends towards hyper-specialization. Recently, several influential reports have emphasized the need to shift educational processes and institutions to a systems approach (see Health professionals for a new century: transforming education to strengthen health systems in an interdependent world Report and the Accelerating Education for the SDGs in Universities Report). 
The field of Planetary Health draws upon approaches to systems thinking that have long been a focus in the field of Ecology. Early work on the concept of "ecosystems" relied on systems thinking to describe the ways by which various elements interact and coalesce as part of complex systems (Odum 1964). Systems thinking in ecology has since shifted from traditionally hierarchical views of ecological processes to webbed representations that integrate the heterogeneous interactions of variables across spatial and temporal scales (e.g., systems ecology (Odum 1964)). More recently, efforts to better understand human-environment interactions (e.g., ecosystem services and Nature's contribution to people) require the consideration of systems across disciplines (IPBES 2019, Díaz 2018, Fiksel 2013).

The Rockefeller Foundation-Lancet Commission Planetary Health report advocates that a systems approach is key in understanding how human health and wellbeing emerge from the complex interactions between natural and social systems. The report notes that systems thinking is essential to better prevent unintended negative consequences of anthropogenic changes to Earth's systems. In this context, systems thinking can be further defined as "a holistic approach for understanding the dynamic interactions among complex economic, environmental, and social systems and for evaluating the potential consequences of interventions" (Fiksel 2013).

\section{The cross-cutting goal of Planetary Health Education within this domain is for learn- ers to be able to collaboratively design and implement transformative solutions to Planetary Health challenges using systems thinking.}

Within Planetary Health, and for the purposes of educational processes, it is essential to characterize the linkages between environmental changes and human health at different geospatial and temporal scales by employing systems-based understandings that incorporate characteristics of complex adaptive systems. Some of these characteristics include non-linear causal relationships, leverage points, emerging characteristics, self-organization, and feedback loops. Moreover, learners require self-awareness and empathy to acknowledge their own biases and epistemological groundings. Learners must be able to appreciate the diverse and evolving nature of knowledge and reflect critically on the influence of heterogeneous actors' perspectives and interests in the process of generating and maintaining knowledge. 


\section{c}

\section{Key concepts and areas of study Complexity and Systems Thinking}

Epistemological diversity and humility

Transdisciplinarity

Uncertainty

Implicit/explicit bias and self-awareness

Unintended/unexpected consequences

Scale, including geographical scale (local/regional/global - micro/meso/macro) and temporal scale (past/present/future - top priority/low priority - urgent/elective)

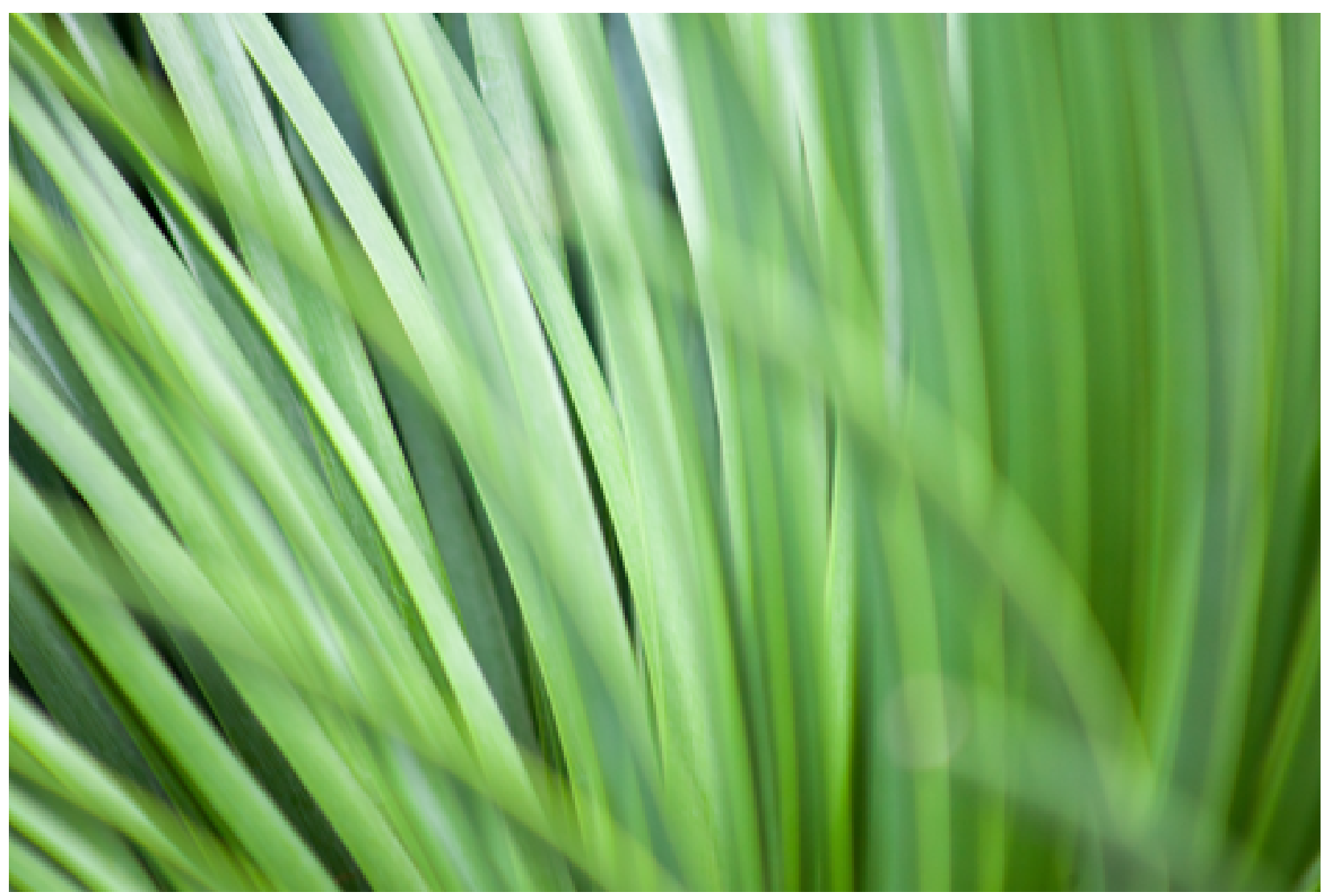

Photo by Rowan Heuvel on Unsplash 


\section{c}
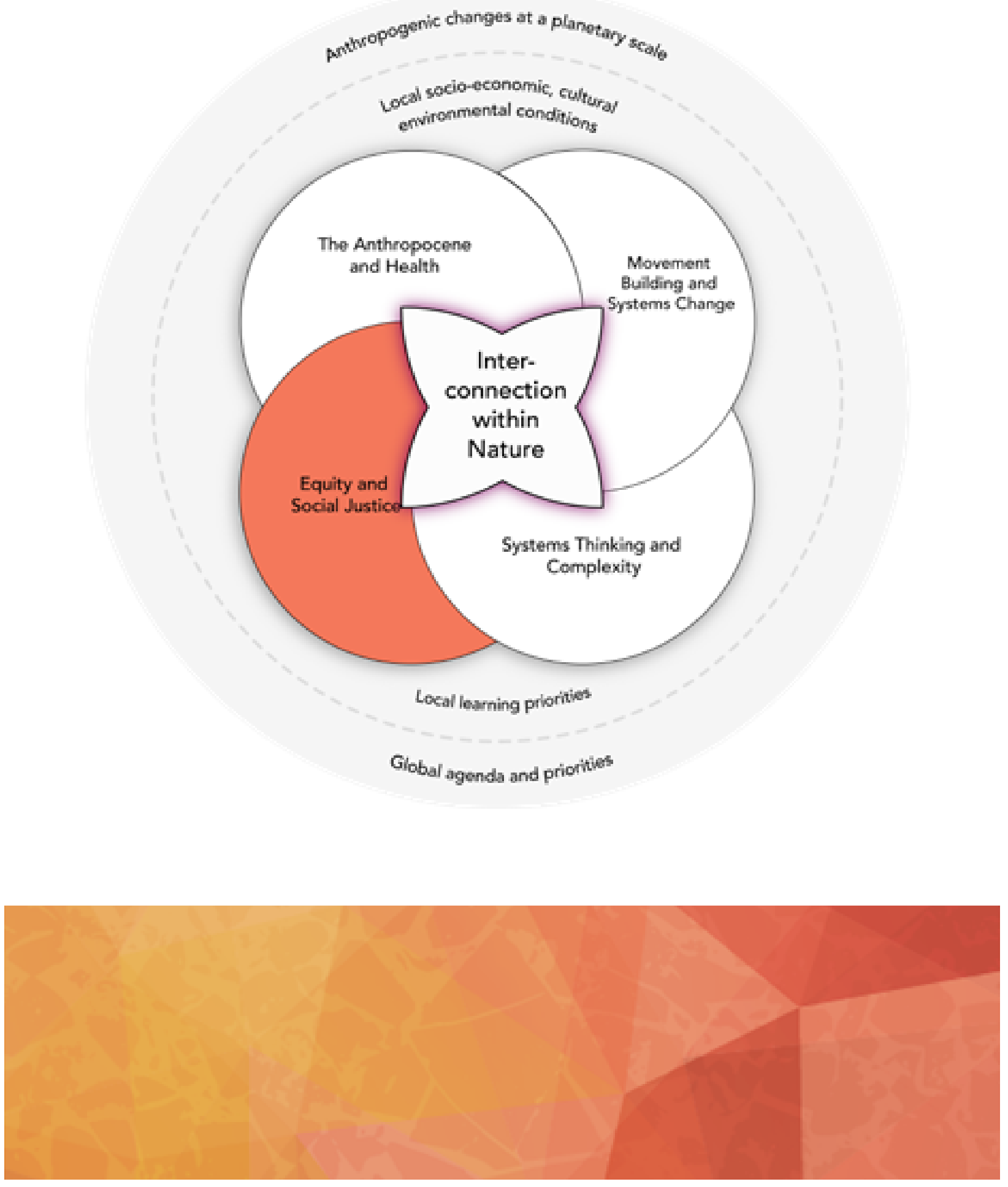


\section{c \\ DOMAIN-EQUITY AND SOCIAL JUSTICE}

"We can work together for a better world with men and women of goodwill, those who radiate the intrinsic goodness of humankind. To do so effectively, the world needs a global ethic with values which give meaning to life experiences and, more than religious institutions and dogmas, sustain the non-material dimension of humanity. Mankind's universal values of love, compassion, solidarity, caring and tolerance should form the basis for this global ethic which should permeate culture, politics, trade, religion and philosophy." - Wangari Maathai

The environmental and health impacts of a changing planet are not distributed fairly across populations, species, geographies, and generations. For example, while the world's high and upper-middle-income countries are responsible for the vast majority of carbon emissions, the burdens of climate change are disproportionately felt by vulnerable populations, including low-income countries, island nations, Indigenous peoples, young and future generations.

Equity in Planetary Health incorporates the rights of humans and rights of Nature, giving all human populations and ecosystems - present and future-the opportunity to attain their full vitality (Prescott et al. 2018; UDRME 2010). To realize a more equitable planet requires eliminating systemic disparities -e.g., power, wealth, opportunity, or health status, so that no population carries disproportionate, avoidabwvle burdens of environmental and health impacts while others are able to thrive. Planetary Health equity also encompasses one of the principles outlined in the Canmore Declaration, "countering elitism, social dominance, and marginalization." To address inequities, attention must be placed on the health and wellbeing of populations and ecosystems most vulnerable to poor health and environmental degradation (Evison \& Bickersteth 2020). These peoples and species are key contributors to solutions addressing the planetary challenges we face.

Promoting Planetary Health equity requires distributive justice-envisioning new ways of sharing burdens-and compensatory justice-ensuring that those who are injured are fairly compensated by those who injure them (Shanks 2012). It also requires social and procedural justice, highlighting inequities, fighting for change, and ensuring that vulnerable groups have opportunities to meaningfully participate in making decisions about policies that affect them. Finally, it is imperative to consider multispecies and intergenerational, environmental justice and equity, which ensures that the actions of the present generation protect the health of future generations. 


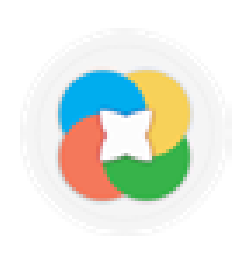

Following an understanding of the connectedness between human-driven changes to our planet and the accompanying consequences to populations described above, solutions must be found to address these challenges (Foster et al. 2020). The Statement of Principles in the Canmore Declaration of 2018, in Canada, drawing from the 1986 Ottawa Charter for Health Promotion, provides guiding principles for Planetary Health ethics necessary in framing potential solutions (Foster et al. 2020; Potvin \& Jones 2011; Prescott et al 2018).

Planetary Health Education processes must first acknowledge the structural inequities and root causes of Planetary Health challenges. Historical and political injustices, including settler-colonialism, white supremacy, racism, patriarchy, capitalism, and neoliberalism, have contributed to the disenfranchisement of populations, including through the degradation of our environment that prevents planetary vitality. In working toward justice, inclusion, diversity and equity, Planetary Health professionals must commit to imagining bold alternatives and implementing practices that address the root causes of injustice within and between societies. Affected groups, including Indigenous Peoples, continue to demonstrate resilience to large-scale environmental and societal changes resulting from ongoing colonial processes. Planetary health practitioners can learn from impacted people by prioritizing their wealth of knowledge for potential solutions (see Interconnection within Nature Domain).

Planetary Health Education must also help students identify priorities for action in order to re-shape the institutions, e.g., laws, health care, education, that reproduce environmental inequities and influence planetary living conditions. Understanding systems of power can enable solutions that improve Planetary Health outcomes. Although interventions aimed at individual and household-level behavior changes continue to gain prominence, this individualistic focus can burden populations already impacted by inequities. In fact, this approach can then result in a distraction from structural, political, and institutional responsibilities to promote Planetary Health. For example, we cannot mitigate climate change without holding accountable the 20 companies responsible for one-third of worldwide carbon emissions. Further, we cannot promote food security without holding accountable the agri-food industry transnational corporations who govern and control the world food system, as noted by the Agrifood Atlas. In order to transform systems of injustice, however, large-scale power movements must continue to build momentum (see next section). 


\section{c}

To promote equity in Planetary Health, it is essential to prioritize the needs of most-affected populations and ecosystems. This includes supporting resilience, strengths-based approaches, the capacity to anticipate and mitigate risks, and a just transition. To accomplish this, professional practice within Planetary Health requires cultural humility, empathy, and the promotion of inclusive and diverse participation in defining solutions. Achieving justice and equity also requires a recognition of one's power, influence, bias, and resources - and a responsibility to use these privileges in working toward a healthier planet, as well as prioritizing the input of the less privileged. Ultimately, learners must be able to apply social justice and equity principles to Planetary Health issues and professional practices.

\section{Key concepts and areas of study Equity And Social Justice}

Accessibility

Equity and Inequity

Social, Distributive, Intergenerational and multispecies Justice

The Rights of Nature

Cultural Humility

Empathy

Privilege

Racism and Oppression 


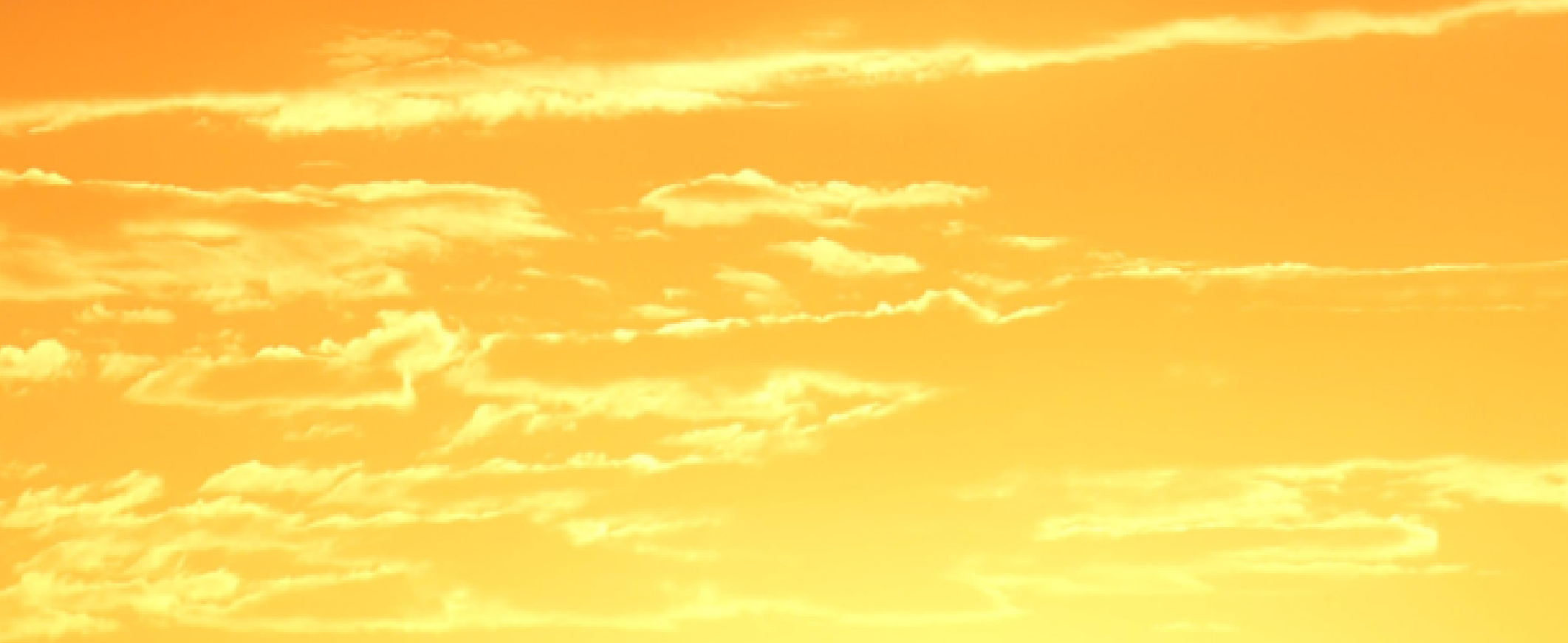




\section{c}
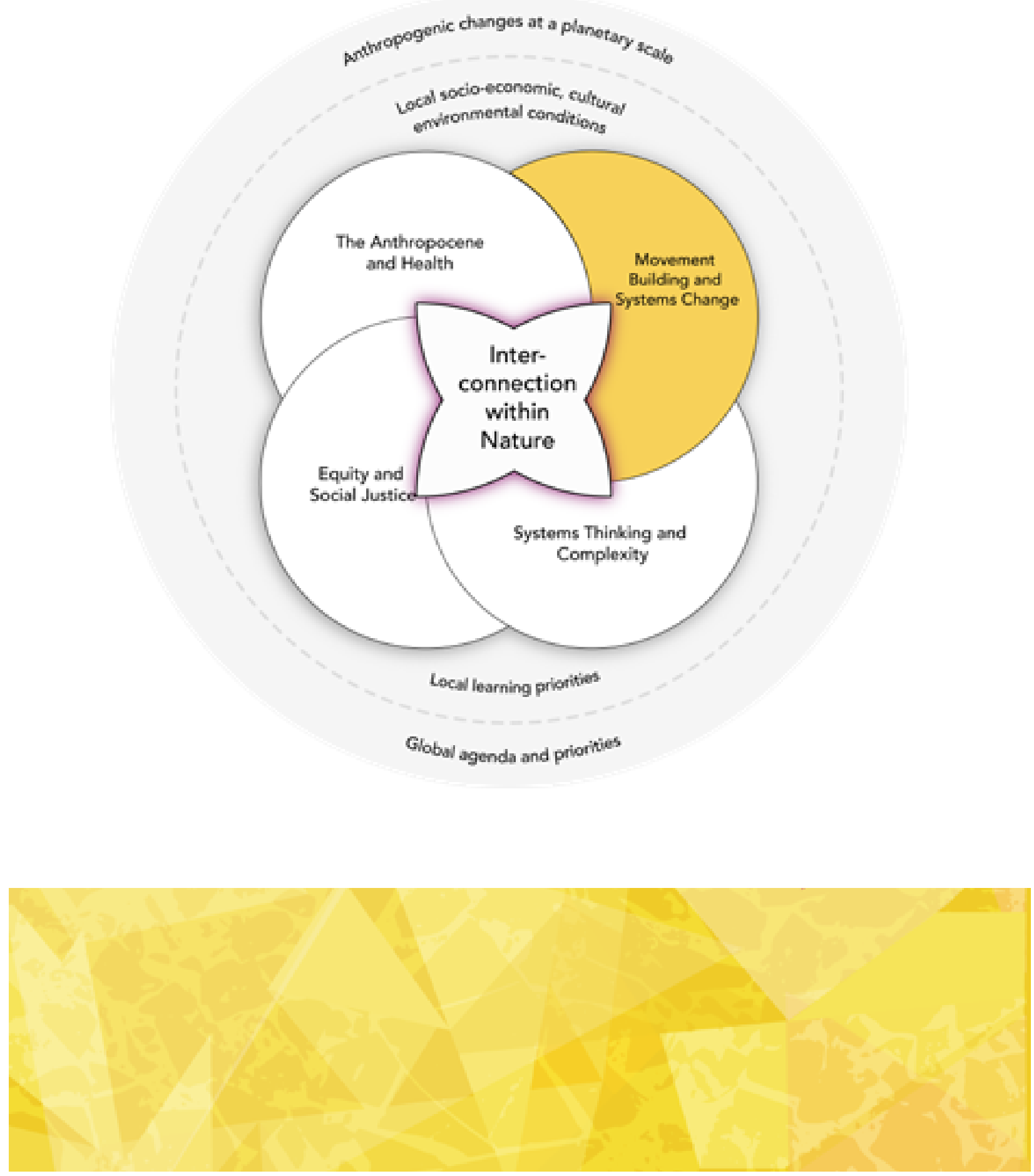


\section{c}

\section{DOMAIN-MOVEMENT BUILDING AND SYSTEMS CHANGE}

"Right here, right now is where we draw the line. The world is waking up. And change is coming whether you like it or not."

- Greta Thunberg

"Never doubt that a small group of thoughtful, committed citizens can change the world; indeed, it is the only thing that

ever has."

- Margaret Mead

We might agree that the health of the planet requires urgent restoration, but the how and who of this process remain unsettled questions. In our vision, change (i.e., action) requires inclusive relationships, thoughtful strategy, effective communication, and transformational partnerships. Hence the movement-building mantra, "Go slow to move fast." The Movement Building and Systems Change domain refers to the necessary skills, knowledge, tools, values, and attitudes learners will require to build a movement that supports systems change and the Great Transition to a just and sustainable future. We believe that a change in shared vision or purpose can profoundly change a system.

Traditionally, higher education, especially liberal arts education, includes an overview of many different fields of knowledge to explore broad challenges yet to be solved. Unfortunately, education frequently does not offer a further narrative to bring these disciplines back together. Students may learn about the health impacts of human-caused disruptions of Earth's natural systems, but they may not learn about effective solutions. Even when they do explore the science of emerging solutions, they may not learn how to build an effective movement for change.

As the Movement Building and Systems Change Domain stresses, effective movement-building is needed to solve the urgent Planetary Health crisis. However, contrary to popular belief, movements do not simply emerge in response to a given moment. It may appear to some that shifts in social behavior can happen quite suddenly, when in fact, it usually takes immense behind-the-scenes visioning, network building, and strategizing (Howard 2020). A small number of individuals can coalesce action for remarkable change. We recognize that it will take a Great Transition to restore Planetary Health, but it will also require a large-scale movement to make it happen. 


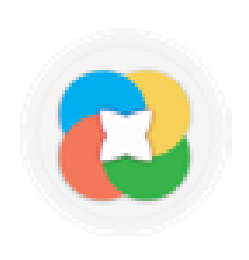

As noted in the Systems Thinking/Complexity-based Approaches in Planetary Health Domain, disciplinary silos thwart the goal of a shared Planetary Health vision. Therefore, recognizing and promoting transdisciplinarity is the first step in coalescing a new vision for Planetary Health. In 1994, at the First World Congress of Transdisciplinarity, the International Center for Transdisciplinary Research (CIRET) adopted the Charter of Transdisciplinarity (ICTR 1994). The Charter states:

"Transdisciplinarity complements disciplinary approaches. It oc-
casions the emergence of new data and new interactions from
out of the encounter between disciplines. It offers us a new vision
of Nature and reality. Transdisciplinarity does not strive for mas-
tery of several disciplines but aims to open all disciplines to that
which they share and to that which lies beyond them" (Article 3).

The second step in creating a shared vision is developing a narrative that focuses on inclusivity and hope. A vision that is capable of driving an effective movement must be able to incorporate different ways of knowing, as well as be grounded in a narrative that extends across core shared values. Marshall Ganz, the renowned community organizing scholar coined the term "Public Narrative" (Howard 2020) to describe the framework for storytelling that "communicates the values that have called us to leadership, the values that unite us, and the challenges that we must overcome together" (Ganz 2008).

Effective movements require healthy relationships both with one's self and others. Learners need to discern what they can uniquely contribute to spur systems change. They need to develop an understanding of the unique interests, knowledge, and skills that they can offer. They must be empowered to learn autonomy in order to both develop and share their personal contributions.

In addition to understanding the unique role(s) learners can play in actualizing Planetary Health solutions, they also need to learn how to develop and maintain networks. Networks connect people across disciplines, geographies, and generations. Networks are strongest when they are broadly inclusive. Networks are the only way to build the capacity required to solve current threats to Planetary Health. 


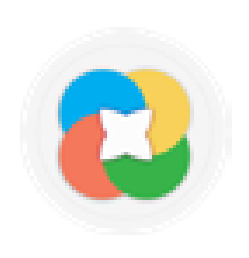

It is essential that these relationships be based on partnership rather than domination. Relationships centered on domination are rigidly ranked-communication only flows topdown, and leaders use shame, blame, and fear to maintain the status quo. In relationships based on partnership, however, there is mutual respect and value for all contributions, such that communication flows both ways and leaders use influence to encourage all network members to achieve their full potential. Differences in the use of power are obvious; leaders who orient toward domination use a "power over" approach, whereas leaders who orient toward partnership use a "power with" approach (Sinnott \& Gibbs 2014).

It is important to note that building healthy partnerships is a process. In order for relationships to remain effective, they cannot be neglected. They must be nurtured and maintained over time. In fact, according to psychologists Sinnott \& Gibbs, "when nurtured over time, relationships sustain motivation and inspiration and become an important source of continual learning and development for the individuals and communities that make up your organizing campaigns" (Sinnott \& Gibbs, 2014, pg. 15).

An effective strategy can unify movement members in their vision and actions. To meet the objectives of this domain, learners should be able to inspire people through a narrative (e.g., in the form of a theory of change) that guides people toward the future they envision. However, even when vision-inspiration is present, and the strategy is effective, changing complex systems can take a long time. It is, therefore, essential for individual activists and movement networks to continue to build capacity, allowing members to lean in and step away as needed to maintain resilience over time. In addition to coalescing a vision, storytelling can remind us of historical challenges that have been overcome by working together, thus giving us hope that future generations will one day tell the story of our successful movement to restore the health of the planet.

\section{Ultimately, we hope students can coalesce visions for a just and sus- tainable future, as well as inspire cross-sector, inclusive partnerships to co-create a better future for all members of Planetary Health.}




\section{c}

Key concepts and areas of study Movement Building and Systems Change

Urgency and hope

Strategic visioning

Theory of Change

The Spectrum of Allies

Advocacy

Entrepeneurship

Innovation

Empowerment, autonomy, and agency

Collaboration - participation

Inclusivity/diversity

Capacity building

Resilience 


\section{(4)}

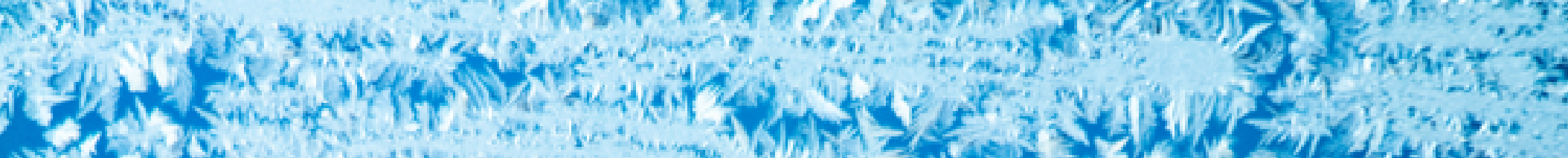
ats

H. 6. Mn instate

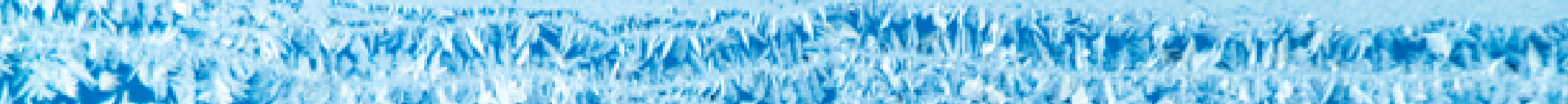

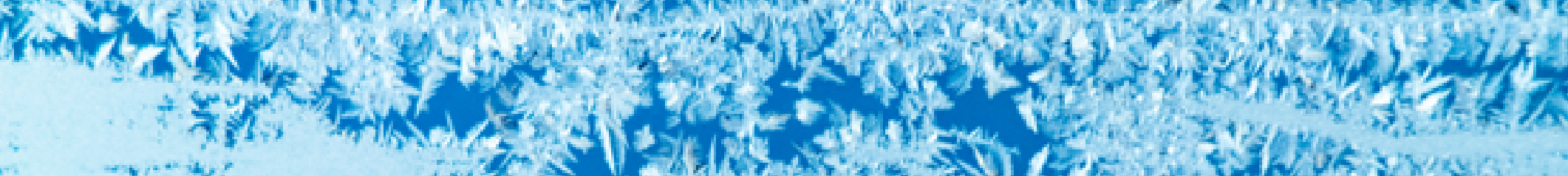

r n

3

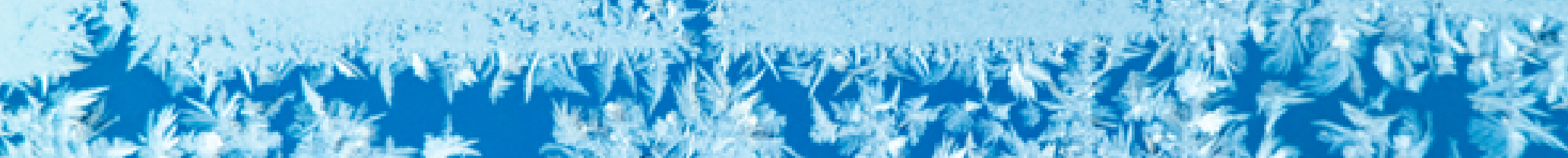
31. Wh 1 - 1 a

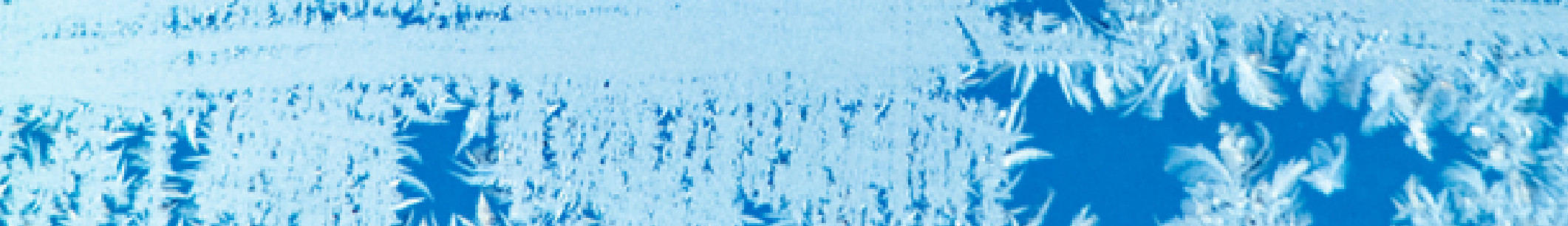

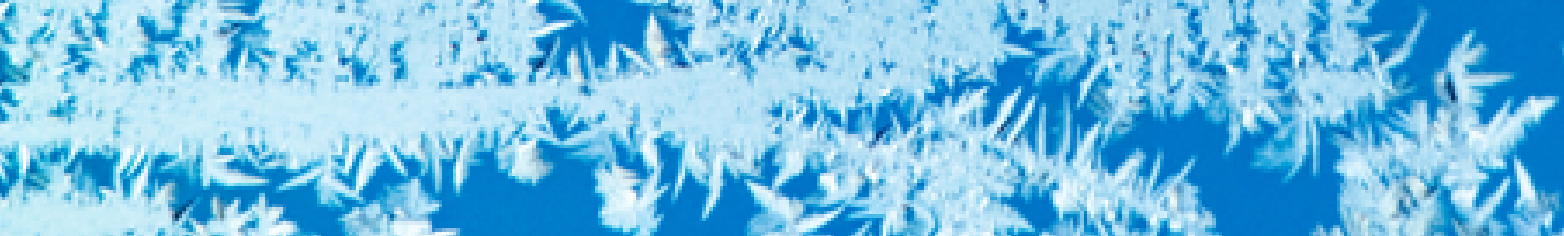

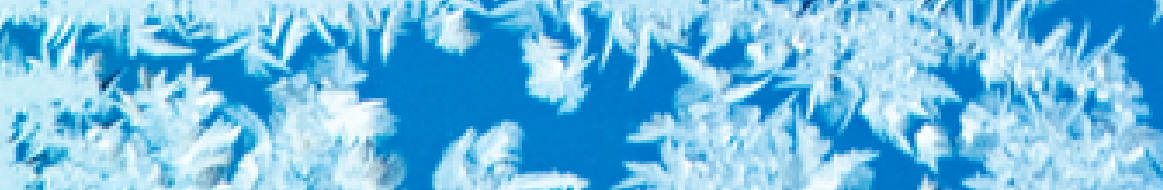

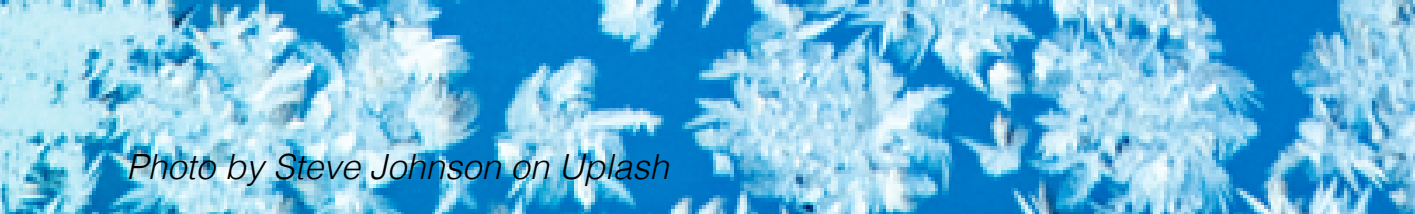

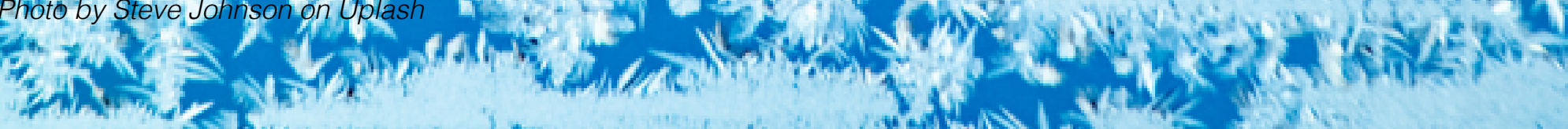




\section{2)}

At this crucial moment in humanity's history, we face choices that impact our own lives and the lives of generations to come. It is up to us to influence human and environmental health both now and in the future, whether it means enhancing our overall wellbeing or risking the health of our planet. As a species, we have made tremendous advancements in our trajectory towards universalizing the most basic human rights: for example, access to education and life-saving technologies, reduction in poverty, increase in life expectancy, and progress towards gender equity. However, the benefits of our advancements have not been equitably distributed, and now, the ongoing disruption of our natural systems risks the loss of our strides forward. Thus, we simply cannot maintain the status quo any longer. Future professionals of all disciplines have a vital role to play in disrupting business-as-usual and building a new equitable, healthy future. However, we cannot achieve the change needed without a profound shift in our education system.

There exist plentiful opportunities to enhance our educational strategies. Never in our history have we been able to connect, communicate, create networks, and disseminate knowledge as in this moment in time. Therefore, despite acknowledging that educational reform is a gradual process, we call for a profound shift in educational approaches hoping that change occurs in an accelerated manner.

Institutions, educators, and learners that decide to incorporate this framework in their educational efforts must transition away from a business-as-usual, siloed approach to education. In order to adapt Planetary Health as a guiding framework for an institution-wide implementation, institution action plans must consider contextualization, transdisciplinarity (including epistemological diversity), a focus on "essential" skills, and solution-oriented, action-based, and transformative approaches to education (AACU 2021). University leadership, policy-makers, educators, and researchers are crucial in the path towards change. Students and young professionals are perhaps more pivotal in driving and sustaining the path forward. As noted in this document, change will only occur sustainably and equitably with the involvement of all stakeholders.

Adopting Planetary Health Education must become a central component to addressing the urgent environmental and health challenges we face. We hope that this transformation in education will foster local and global communities to work towards well-being, justice, and a thriving planet for all. 


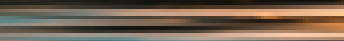

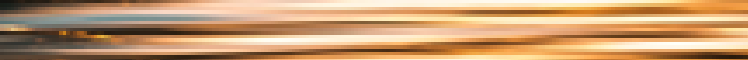




\section{Key Definitions}

\section{Agency}

"The capacity of an individual to actively and independently choose and to affect change; free will or self-determination" (OESD 2021).

\section{Anthropocene}

A concept marking the start of a proposed geologic epoch in which the dominant force shaping Earth's biophysical conditions is human activity. The term combines the Greek roots "anthropo-," meaning "human," with kainos or "-cene" the standard suffix for "epoch" in geologic time. Nobel laureate Paul J. Krutzen and Eugene Stoermer coined the word in an essay for an earth systems science(Steffen et al. 2015).

\section{Complex systems}

Refers to systems that are composed of a large number of interacting components, without central control, whose emergent "global" behavior-described in terms of dynamics, information processing, and/or adaptation -is more complex than can be explained or predicted from understanding the sum of the behavior of the individual components. Complex systems are generally capable of adapting to changing inputs/environment and in such cases sometimes referred to as complex adaptive systems.

\section{Determinants of Health}

According to the World Health Organization, the Determinants of Health include: "the social and economic environment, the physical environment, and the person's individual characteristics and behaviours.

The context of people's lives determine their health, and so blaming individuals for having poor health or crediting them for good health is inappropriate. Individuals are unlikely to be able to directly control many of the determinants of health. These determinants-or things that make people healthy or not-include the below factors, and many others: 
Income and social status - higher income and social status are linked to better health. The greater the gap between the richest and poorest people, the greater the differences in health.

Education - low education levels are linked with poor health, more stress and lower self-confidence.

Physical environment - safe water and clean air, healthy workplaces, safe houses, communities and roads all contribute to good health. Employment and working conditions - pveople in employment are healthier, particularly those who have more control over their working conditions

Social support networks - greater support from families, friends and communities is linked to better health. Culture - customs and traditions, and the beliefs of the family and community all affect health.

Genetics - inheritance plays a part in determining lifespan, healthiness and the likelihood of developing certain illnesses. Personal behaviour and coping skills - balanced eating, keeping active, smoking, drinking, and how we deal with life's stresses and challenges all affect health.

Health services - access and use of services that prevent and treat disease influences health

Gender - Men and women suffer from different types of diseases at different ages.

\section{Determinants of Health in Animals}

Determinants of health applied to animals may include individual and population biology; the animal's social environment; quantity and quality of habitat to fulfill basic animal's needs; the abiotic environment; sources of direct mortality; and changing human expectations (5). Determinants used in human and public health are different for animals, plants and ecosystems. This distinction is relevant if applied for planning, development of policy, and guiding of research. Models for other species may help managers identify health protection priorities and to promote actions for wildlife and their habitats.

\section{Epistemological Diversity}

"Epistemic diversity is the ability or possibility of producing diverse and rich epistemic apparati to make sense of the world around us" (Gobbo \& Russo 2019). Given diverse knowledge paradigms stemming from cultures around the world, it is essential that scholars and educators be familiar with and consider the integration of different epistemologies. In fact, epistemological diversity can shed light on improved pathways toward Planetary Health. 


\section{Equity}

Equity encapsulates the ability for fairness through access to the same resources and opportunities. Given current social disparities in financial capital, education, health, food, housing, etc., equity may involve the disproportionate distribution of resources to a certain population in order to lift them onto the same playing field as others.

\section{Global Environmental Change}

Pervasive, accelerating changes and disruptions of Earth's natural systems including climate change, biodiversity loss, changes in land use and land cover, resource scarcity, global pollution, and altered biogeochemical cycles. These changes to Earth's biophysical conditions are different from the types of environmental change classically addressed by the field of environmental health which focuses on the introduction of heavy metals, endocrine disruptors, PCBs, and other human-introduced toxins into our environment.

\section{Inclusivity/diversity}

Inclusivity and diversity go hand in hand, as we must be accepting of each other's differences. Generally, diversity refers to differences in race, ethnicity, gender, sexual orientation, religion, age, national origin, socioeconomic status, language, perspectives, epistemologies, values, and much more. Inclusion brings together "traditionally excluded individuals and/or groups into processes, activities, and decision/policy making in a way that shares power" (ICMA Glossary).

\section{Indigenous Peoples}

"Indigenous Peoples are distinct social and cultural groups that share collective ancestral ties to the lands and natural resources where they live, occupy or from which they have been displaced. The land and natural resources on which they depend are inextricably linked to their identities, cultures, livelihoods, as well as their physical and spiritual wellbeing. They often subscribe to their customary leaders and organizations for representation that are distinct or separate from those of the mainstream society or culture. Many Indigenous peoples still maintain a language distinct from the official language or languages of the country or region in which they reside" (World Bank, Indigenous Peoples). 


\section{Indigenous Traditional Knowledge (ITK)}

ITK "refers to the knowledge, innovations and practices of Indigenous peoples. Developed from experience gained over the centuries and adapted to the local culture and environment, traditional knowledge is often transmitted orally from generation to generation. It tends to be collectively owned and can be expressed in stories, songs, folklore, proverbs, cultural values, beliefs, rituals etc. It is also the source for the traditional use and management of lands, territories and resources, with Indigenous agricultural practices that care for the Earth, without depleting the resources. Indigenous peoples follow oral traditions, with dances, paintings, carvings and other artistic expressions, that are practiced and passed down through millennia" (United Nations 2019).

\section{Interconnection}

Describes the non-dualistic state of being that exists within Nature. For humans, the experience of interconnection within Nature has been described as "A stable state of consciousness comprising symbiotic cognitive, affective, and experiential traits that reflect, through consistent attitudes and behaviors, a sustained awareness of the interrelatedness between one's self and the rest of nature" (Zylstra et al. 2014).

\section{Kincentric Ecology}

"Indigenous people view both themselves and Nature as part of an extended ecological family that shares ancestry and origins. It is an awareness that life in any environment is viable only when humans view the life surrounding them as kin. The kin, or relatives, include all the natural elements of an ecosystem. Indigenous people are affected by and, in turn, affect the life around them. The interactions that result from this "kincentric ecology" enhance and preserve the ecosystem. Interactions are the commerce of ecosystem functioning. Without human recognition of their role in the complexities of life in a place, the life suffers and loses its sustainability." (Salmon 2000, pg. 1327).

\section{Nature}

Frequently understood as the non-human biophysical system which includes flora, fauna, and geological landforms occurring across a range of scales and degrees of human presence (Zylstra et al. 2014). In attempting to overcome this conceptual and perceptual human/nature divide and in acknowledging many non-Western cultural conceptualizations, we suggest that "Nature" is by default "earth and life (including humans)". 


\section{Planetary Boundaries}

According to the Stockholm Resilience Centre, "The planetary boundaries concept presents a set of nine planetary boundaries within which humanity can continue to develop and thrive for generations to come." These nine boundaries include: stratospheric ozone depletion, loss of biosphere integrity (biodiversity loss and extinctions), climate change, ocean acidification, freshwater consumption and the global hydrological cycle, land system change, nitrogen and phosphorus flows to the biosphere and oceans, and atmospheric aerosol loading.

\section{Planetary Health}

A rapidly emerging field focused on understanding, communicating, and addressing the extensive human health threats associated with rapidly changing environmental conditions. These include climate change, biodiversity loss, changes in land use and land cover, resource scarcity, global pollution, and altered biogeochemical cycles.

or

An emerging field focused in understanding the dynamic interlinkages between anthropogenic variations to the Earth's natural systems and human health at various scales, and using these emerging understandings to find solutions that integrate the wellbeing of our biosphere

or

"Human health and Planetary Health are the same thing...To harm the Earth is to harm the self" (Prescott 2018, pg.10).

\section{Praxis}

Praxis bridges the separation between theory and practice. Freire (1972) described praxis as "reflection and action upon the world in order to transform it." Praxis is fundamentally built on the importance of committing to social justice and systems change. It ensures the consideration of social, political, economic, and natural factors in research and application.

\section{Resilience}

The American Psychological Association defines resilience as "the process of adapting well in the face of adversity, trauma, tragedy, threats, or significant sources of stress-such as family and relationship problems, serious health problems, or workplace and financial stressors. As much as resilience involves "bouncing back" from these difficult experiences, it can also involve profound personal growth." Southwick et al. (2014) expand on this definition, understanding that "determinants of resilience include a host of biological, psychological, social and cultural factors that interact with one another to determine how one responds to stressful experiences" (Southwick et al. 2014). 


\section{Social, Environmental, Distributive, Intergenerational and Multispecies Justice}

Most fundamentally, justice is the concept of fairness. Social, environmental, distributive, intergenerational, and multispecies justice extends the concept of fairness to societal structures, environmental systems, species, and ecosystems through the consideration of geographical and temporal distributions.

\section{Systems Thinking}

Systems thinking aims to connect elements to each other within some notion of a whole entity. Systems thinking focuses on stems thinking by using explicit models (clear assumptions) rather than mental implicit models (i.e., unrevealed assumptions and missing or lack of data points). This viewpoint thereby helps identify and communicate underlying assumptions, as well as provide a basis for models to be reproduced by others. Systems thinking has origins and applications in many different fields and theories. In essence, it requires a transdisciplinary approach to conceptualize, model, and understand complex phenomena in order to induce beneficial changes.

Systems thinking can be further defined as "a holistic approach for understanding the dynamic interactions among complex economic, environmental, and social systems and for evaluating the potential consequences of interventions" (Fiksel 2013). Systems thinking is therefore essential to better prevent unintended negative consequences of anthropogenic changes to Earth's systems.

\section{The Great Acceleration}

A global change after the second world war manifesting in a massive growth rate of human activities and changing demographics beginning around 1950. According to the International Geosphere-Biosphere Programme, "the second half of the 20th Century is unique in the history of human existence. Many human activities reached take-off points sometime in the 20th Century and sharply accelerated towards the end of the century. The last 60 years have without doubt seen the most profound transformation of the human relationship with the natural world in the history of humankind" (IGBP 2015). 


\section{The Great Transition}

A fundamental shift in how people and human systems - political, economic, and social - interact to shape the highest attainable standards for the health of humanity and the state of Earth's natural systems. It is a transformation of values from individualism, consumerism, and domination of Nature to solidarity, quality of life, and ecological resilience. It can be measured and thus attained via improving the health of the environment, breadth of human solidarity, and quality of all lives (Raskin et al. 2002).

\section{Transdisciplinarity}

As defined by the Harvard School for Public Health, "Transdisciplinary Research is defined as research efforts conducted by investigators from different disciplines working jointly to create new conceptual, theoretical, methodological, and translational innovations that integrate and move beyond discipline-specific approaches to address a common problem."

However, transdisciplinarity can also be extended to include a way of being. Rigolot (2020) explains that "when transdisciplinarity is considered as a way of being, it is inseparable from personal life and extends far beyond the professional activities of a researcher" (Rigolot 2020).

"Transdisciplinarity acknowledges that one academic or disciplinary mode of research is ill-equipped to understand, let alone address, the complex challenges facing present-day society and given the diversity of perspectives involved. Instead, it encourages shared learning processes that involve society and allow for problems to be defined, researched and solved independently of any single (scientific) discipline. Another important trait of transdisciplinary research is that it complements traditional scientific criteria for 'objectivity' (in e.g. the natural sciences) with the subjective and normative domains in which societal worldviews, values and ethics are expressed. In bridging these divides, the relevance and ability for science to address social-ecological problems is enhanced through the likelihood that the research (the 'knowing') will be effectively used in implementation (the 'doing'). Transdisciplinary approaches are therefore vital to sustainability science." (Zylstra 2014) 


\section{$\underline{\text { References }}$}

Agrifood Atlas: Facts and figures about the corporations that control what we eat. (20 I 7). https://in.boell.org/ sites/default/files/agrifoodatlas2017_facts-and-figures-about-the-corporations-that-control-what-we-eat.pdf

Aguirre A.A., G.M.Tabor and R.S. Ostfeld. 20 12. Conservation medicine: Ontogeny of an emerging discipline. In A.A. Aguirre., R. S. Ostfeld and P. Daszak, eds. New Directions in Conservation Medicine: Applied Cases of Ecological Health, Oxford University Press, New York, pp. 3-16.

American Association of Colleges and Universities in Hovland, K., 20 I 4. Global learning: Defining, designing, demonstrating. American Association of Colleges and Universities.

American Psychological Association. (20 I 2). Building your resilience. https://www.apa.org/topics/resilience

Antoine, A., Mason, R., Mason, R., Palahicky, S. \& Rodriguez de France, C. (20I8). Pulling together: A guide for curriculum dvwevelopers. BCcampus. https:/opentextbc.ca/indigenizationcurriculumdevelopers/

Arends, R. I. (1998). Resource handbook. Learning to teach (4th ed.). Boston, MA.

Association of American Colleges \& Universities. (202I). Essential Learning Outcomes. https://www.aacu.org/ essential-learning-outcomes

Bartlett, C., Marshall, M., \& Marshall, A. (2012). Two-Eyed Seeing and other lessons learned within a co-learning journey of bringing together indigenous and mainstream knowledges and ways of knowing. Journal of Environmental Studies and Sciences, 2, 33 I-340. doi.org/ I 0. I007/s I 34 I 2-0 I 2-0086-8

Barnhardt, R., \& Kawagley, A.O. (2005). Indigenous knowledge systems and Alaska Native ways of knowing. Anthropology and Education Quarterly, 36(I), 8-23. https://www.fws.gov/nativeamerican/pdf/tek-barnhardt-kawagley.pdf

Card C., Epp, T., and Lem, M. (2018). Exploring the social determinants of animal health. Journal of Veterinary Medical Education, 45(4), 437-447. doi: I 0.31 38/jvme.03 I7-047r

Cusicanqui, S., Taddei, R., Hornborg, A., Szerszynski, B., Süssekind, F., Fausto, J., Cavalieri, C., Medeiros, R., and Santilli., M (20I5). The Thousand Names of Gaia: from the Anthropocene to the Age of the Earth. https:// thethousandnamesofgaia.wordpress.com/ 
Díaz, S., Pascual, U., Stenseke, M., Martín-López, B., Watson, R.T., Molnár, Z., Hill, R., Chan, K.M., Baste, I.A., Brauman, K.A. and Polasky, S. (2018). Assessing nature's contributions to people. Science, 359(6373), 270-272.

Díaz, S., Settele, J., Brondízio, E. S., Ngo, H.T., Agard, J., Arneth, A., .. Zayas, C. N. (2019). Pervasive human-driven decline of life on Earth points to the need for transformative change. Science, 366(647I). doi: 10.1 126/science.aax3100

Eisler, R., \& Potter,T. (20।4).Transforming interprofessional partnerships: A new framework for nursing and partnership-based health care. Sigma Theta Tau International.

Evison, W., \& Bickersteth, S. (2020). A new economics for Planetary Health. (Chapter I 5, pp. 387 - 424). In S. Myers \& H. Frumkin (Eds.). Planetary health: protecting Nature to protect ourselves. Island Press.

Fiksel J, Bruins R, Gatchett A, Gilliland A,Ten Brink M. (20I 3). The Triple Value Model: a systems approach to sustainable solutions. Clean Technology \& Environmental Policy, I6, 69 I-702.

Foster, A., Cole, J., Farlow, A., \& Petrikova, I. (2019). Planetary health ethics: beyond first principles. Challenges, $10(1), 14$.

Foster, A., Cole, ., Petrikova, I., Farlow, A., \& Frumkin, H. (2020). Planetary health ethics (Chapter I7, pp. 453-474). In S. Myers \& H. Frumkin (Eds.). Planetary health: protecting Nature to protect ourselves. Island Press.

Frenk, J., Chen, L., Bhutta, Z.A., Cohen, J., Crisp, N., Evans, T., Fineberg, H., Garcia, P., Ke,Y., Kelley, P. and Kistnasamy, B. (20 I0). Health professionals for a new century: transforming education to strengthen health systems in an interdependent world. The Lancet, 376(9756), pp. I 923- 1958.

Freire, P. (2018). Pedagogy of the oppressed. Bloomsbury publishing.

Ganz, M. (2008). Leading change: Leadership, organization, and social movements. https://www.researchgate.net/profile/Marshall_Ganz/publication/266883943_Leading_Change_Leadership_Organization_and_Social_Movements/links/57 I8c2d508aed8a339e5c6 10/Leading-Change-Leadership-Organization-and-Social-Movements.pdf

Gobbo, F., \& Russo, F. (2020). Epistemic diversity and the question of Lingua Franca in science and philosophy. Foundations of Science, 25(I), I 85-207. 
Harmin, M., Barrett, M. J., \& Hoessler, C. (2017). Stretching the boundaries of transformative sustainability learning: On the importance of decolonizing ways of knowing and relations with the morethan-human. Environmental Education Research, 23( I 0), I 489- I 500. doi.org/ | 0. I 080/I3504622.20 I 6.1263279

Harvard School for Public Health. (202I). https://www.hsph.harvard.edu/

Horton, R., 2020. Offline: COVID-19 is not a pandemic. Lancet (London, England), 396( I 0255), p.874.

Howard, C. (2020).Targeted change making for a healthy recovery. The Lancet: Planetary Health, 4(9), https://doi.org/ / 0.10 | 6/S2542-5 196(20)30200-X

Hunt, S. (20 I 3). Ontologies of Indigeneity: the politics of embodying a concept. Cultural Geographies, 2I ( I), 27-32. DOI: I0.1 I77//4744740 I3500226

ICMA. (202I). Glossary ofTerms: Race, Equity and Social Justice. https://icma.org/glossary-terms-race-equity-and-social-justice

IGBP. (20 I5). Great Acceleration. http://www.igbp.net/globalchange/greatacceleration.4. I b8ae205 I 2db692f2a68000 I 630.html

International Center forTransdisciplinary Research. (1994). Charter of Transdisciplinarity. https:// basarab-nicolescu.fr/chart.php\#en International Panel on Climate Change. (2007). Evidence for Changes in Tropical Storms.WMO, UNEP. https://archive.ipcc.ch/publications_and_data/ar4/wgl/en/ch3s3-8-3.html

IPBES. (2019). Global assessment report on biodiversity and ecosystem services of the Intergovernmental Science-Policy. Platform on Biodiversity and Ecosystem Services. E. S. Brondizio, J. Settele, S. Díaz, and H.T. Ngo (editors). https://ipbes.net/global-assessment

Kuo, M. (20 I5) How might contact with Nature promote human health? Promising mechanisms and a possible central pathway. Frontiers of Psychology, 6( I 093), I-8. doi: 10.3389/fpsyg.20 I 5.01093

Lewis, S. L. \& Maslin, M. A. (20 I5). Defining the Anthropocene. Nature 5 I9(7542), I 7 I - 80.

Martinez, D. (2008). Native perspectives on sustainability: Dennis Martinez (O'odham/Chicano/Anglo). Interview by David E. Hall. https://www.nativeperspectives.net/Transcripts/Dennis_Martinez_interview.pdf

McGraw-Hill \& Vygotsky, L. S. (1978). Mind in society:The development of higher psychological processes. Harvard University Press. 
Meadows D.H. (2008). Thinking in Systems: A Primer. Edited by Diana Wright, Sustainability Institute. Chelsea Green Publishing.

Meyer, A., Rose, D.H. and Gordon, D.T. (20/4). Universal design for learning: Theory and practice. CAST Professional Publishing.

Millennium Ecosystem Assessment (Program). (2005). Ecosystems and human wellbeing. Island Press.

Muller, S. (2012).Two Ways. In Country, Native Title and Ecology (Vol. 24, p. 59). ANU E Press. http://press.anu.edu.au?p=|7504|

Myers, S., \& Frumkin, H. (2020). Planetary Health: Protecting Nature to Protect Ourselves. Island Press.

Myers, S.S. (2017). Planetary health: protecting human health on a rapidly changing planet. The Lancet.

Nicolescu, B., Morin, E., \& de Freitas, L. (1994). The charter of transdisciplinarity. In First World Congress on transdisciplinarity. Convento de Arrabida, Portugal.

Odum, E.P. (1964). The new ecology. BioScience |4, I 4- | 6. https://www.jstor.org/stable/ 1293228 ?seq = I

Open Education Sociology Dictionary. (202I). Agency. https://sociologydictionary.org/agency/

Otto, S., \& Pensini, P. (20 I7). Nature-based environmental education of children:

Environmental knowledge and connectedness to Nature, together, are related to ecological behavior. Global Environmental Change, 47, 88-94. https://www.sciencedirect.com/science/article/abs/pii/ S09593780I 6305787

Peng, Wanxi, Ma, Nyuk Ling, Zhang, Dangquan, Zhou, Quan, Yue, Xiaochen, Khoo, Shing Ching, ... Sonne, Christian. (2020). A review of historical and recent locust outbreaks: Links to global warming, food security and mitigation strategies. Environmental Research, 191, I I 0046.

Planetary Health Alliance. (202I). https://www.planetaryhealthalliance.org/PHA

Potvin, L., \& Jones, C. (20I I). Twenty-five years after the Ottawa Charter: the critical role of health promotion for public health. Canadian Journal of Public Health, I02(4), 244-248.

Prescott, S.L., Logan, A.C., Albrecht, G., Campbell, D.E., Crane, J., Cunsolo, A., Holloway, J.W., Kozyrskyj, A.L., Lowry, C.A., Penders, J., Redvers, N., Renz, H., Stokholm, J., Svanes, C., Sustainable Development Solutions Network. (2020). Accelerating Education for the SDGs in 
Public Health Agency of Canada. (1986). Ottawa Charter for Health Promotion: An International Conference on Health Promotion. Health and Wellness Canada. http://www.phac-aspc.gc.ca/ph-sp/ docs/charter-chartre/pdf/charter.pdf

Radford, Tim. (2019). James Lovelock at 100:The Gaia saga continues. Nature (London), 570(7762), $44 \mid-442$.

Raskin, P., Banuri, T., Gallopin, G., Gutman, P., Hammond, A., Kates, R. and Swart, R., 2002. Great transition:The promise and lure of the times ahead (Vol. I). Boston: Stockholm Environmental Institute.

Redvers, N. (20 I 8). The value of global indigenous knowledge in planetary health. Challenges, 9(2), 30. https://doi.org/ 10.3390/challe9020030

Redvers, Nicole, Bird, Michael Yellow, Quinn, Diana, Yunkaporta, Tyson, \& Arabena, Kerry. (2020). Molecuvvlar Decolonization: An Indigenous Microcosm Perspective of Planetary Health. International Journal of Environmental Research and Public Health, I7( I 2), 4586. https://pubmed.ncbi.nlm. nih.gov/32630572/

Revkin A. (2016). An Anthropocene journey. Anthropocene Magazine, I https://www.anthropocenemagazine.org/anthropocenejourney/

Rigolot, C. (2020). Transdisciplinarity as a discipline and a way of being: Complementarities and creative tensions. Humanities \& Social Sciences Communications, 7( I), I-5.

Salmón, E. (2000). Kincentric ecology: Indigenous perceptions of the human-nature relationship. Ecological Applications, I0(5), I 327- I332. DOl: 10.2307/264I288

Shanks, T., Andre, C., Velasquez, M. and Meyer, M.J. (2012). Justice and fairness.

Sinnott, S., \& Gibbs, P. (20।4). Organizing: People, power, change. https://commonslibrary.org/organizing-people-power-change/

Southwick, Steven M, Bonanno, George A, Masten, Ann S, Panter-Brick, Catherine, \& Yehuda, Rachel. (20।4). Resilience definitions, theory, and challenges: Interdisciplinary perspectives. European Journal of Psychotraumatology, 5( I ), 25338-Article 25338.

Steffen, W., Broadgate, W., Deutsch, L., Gaffney, O. and Ludwig, C. (20 I 5). The trajectory of the Anthropocene: the great acceleration. The Anthropocene Review, 2(I), pp.8 I-98. https://journals. sagepub.com/doi/abs/ I 0.I | 77/20530 | 96 | 4564785 
Stockholm Resilience Centre. Planetary Boundaries. https://www.stockholmresilience.org/research/ planetary-boundaries.html

Stone, S. B., Myers, S. S., \& Golden, C. D. (20 I 8). Cross-cutting principles for Planetary Health Education. The Lancet Planetary Health, 20, 192-193. https://www.thelancet.com/journals/lanplh/article/ PIIS2542-5 I96(I 8)30022-6/fulltext

Tansley, A.G. (1935). The use and abuse of vegetational concepts and terms. Ecology 16, 284-307.

United Nations. (2019). The United Nations permanent forum on Indigenous issues:Together we achieve. https:/www.un.org/development/desa/indigenouspeoples/wp-content/uploads/ sites/19/20 I9/04/Traditional-Knowledge-backgrounder-FINAL.pdf

Universities: A guide for universities, colleges, and tertiary and higher education institutions. https:// resources.unsdsn.org/accelerating-education-for-the-sdgs-in-universities-a-guide-for-universities-colleges-and-tertiary-and-higher-education-institutions

Universal Declaration of the Rights of Mother Earth. (20 I0).World People's Conference on Climate Change and the Rights of Mother Earth. https://www.eldis.org/document/A59434\#: : tex$\mathrm{t}=$ This\%20is\%20a\%20proclamation\%20of,Bolivia\%20on\%20April\%2022\%2C\%2020 I 0.\&text=declares\%20that\%20ME\%20and\%20all,life\%2C\%20 existence\%2C\%20respect\%20and\%20continuity

Verschuuren, B., Zylstra, M., Yunupingu, B., \& Verschoor, G. (20I5). Mixing Waters: A Cross Cultural Approach to Developing Guidelines for Fishers and Boaters in the Dhimurru Indigenous Protected Area, Australia. Parks. 2 I ( I), 74-88. https://doi.org/ I0.2305/iucn.ch.20 I4.parks-2 I - I bv.en

Wegienka, G. (20।8). The Canmore Declaration: Statement of principles for planetary health. Challenges, 9(2), 3 I. https://doi.org/|0.3390/challe902003 I

Whitmee, S., Haines, A., Beyrer, C., Boltz, F., Capon, A. G., de Souza Dias, B. F., ... \& Horton, R. (20 I5). Safeguarding human health in the Anthropocene epoch: report of The Rockefeller FoundationLancet Commission on planetary health. The Lancet, 386( I 0007), I973-2028. https://www.thelancet.com/journals/lancet/article/PIISO I 40-6736( I 5)6090 I - I/fulltext?nr_email_referer= I)

Wilcox, B.A., Aguirre, A.A., De Paula, N., Siriaroonrat, B. and Echaubard, P., 2019. Operationalizing one health employing social-ecological systems theory: lessons from the greater Mekong sub-region. Frontiers in public health, 7, p.85. 
World Bank. (n.d.). Indigenous peoples. https:/www.worldbank.org/en/topic/indigenouspeoples

World Health Organization. (2017). Determinants of Health. https://www.who.int/news-room/q-adetail/determinants-of-health

Zylstra, M. J., Knight, A.T., Esler, K.J., \& LeGrange, L.L.L. (20 I4). Connectedness as a core conservation concern: An interdisciplinary review of theory and a call for practice. Springer Science Reviews, 2, | |9-|43. DOI | 0.1007/s40362-0| 4-002|-3

Zylstra, M.J., 20I4. Exploring meaningful nature experience, connectedness with nature and the revitalization of transformative education for sustainability (Doctoral dissertation, Stellenbosch: Stellenbosch University). 


\section{ANNEX I. Collated competency statements that served to guide the creation of the Planetary Health Education Framework}

I. Identify how anthropogenic changes to natural systems influence health outcomes

2. Understand the disproportionate impact of climate and other environmental changes on Indigenous peoples, and the strength of Indigenous ways of knowing and doing in helping to build an equitable relationship between people and the environment

3. Incorporate traditional knowledge systems, including indigenous worldviews, into Planetary Health action.

4. Implement strategies to engage marginalized and vulnerable populations in making decisions that affect the health and well-being of populations and ecosystems.

5. Use ethical, empowering, culturally appropriate, and participatory processes to implement Planetary Health action.

6. Describe how cultural context influences perceptions of health and disease, as well as people's relationship with their natural and built environment.

7. Examine the interactions between the geographical scale (local/regional/global - micro/meso/macro), temporal scale (past/present/future - top priority/low priority - urgent/elective) and socioeconomic factors, and political and cultural context that shapes the Planetary Health landscape.

8. Apply ethical principles and frameworks to issues, challenges, and professional practices related to Planetary Health, related, but not limited to: Priority setting, Resource distribution, Precautionary principle, Use of appropriate technology, Cultural and traditional knowledge, Subjective moralities, and Power dynamics

9. Develop and communicate appropriate, realistic and measurable goals and objectives for Planetary Health

10. Understand crucial linkages, cause-effect relationships, non-linear relationships, leverage points, uncertainty, and feedback loops between socio-ecological changes and human health.

II. Integrate concepts of equity, transgenerational justice, marginalization, poverty-cycle, power structures, planetary boundaries, vulnerability, resilience into Planetary Health analysis, and action.

12. Support empowerment, participation, partnership, and equity to create environments that promote the health of communities and the planet.

13. Apply social justice and human rights principles in addressing Planetary Health problems.

14. Examine how historical, anthropological, economic, and political contexts of our society(ies) determine our Planetary Health predicament today

15. Demonstrate the ability to work collaboratively across disciplines, recognizing a variety of perspectives, skills and approaches and how they complement each other in collaborative processes and outcomes

16. Advocate with, and on behalf of individuals, communities, and organizations to improve the health and well-being of humans and the environment. 
17. Collects, appraises, and collates/synthesizes/integrates relevant qualitative and quantitative data, info rmation, and literature to inform Planetary Health action.

18. Share knowledge, skills, and resources for enhancing Planetary Health programs, infrastruture, and workforce with a focus on capacity strengthening.

19. Effectively communicate using appropriate techniques and technology, both orally and in writing, scientific findings to the scientific community, non-Planetary Health-related experts, lay audiences, media, and policymakers.

20. Appreciate and recognize the sources of uncertainty and be able to or have capacity to pre dict the unexpected consequences of environmental change, both positive and negative.

21. Understand historical perspectives and milestones that have laid the foundation for the field of Planetary Health, including perspectives that have been marginalized or ignored.

22. Use appropriate evaluation and research methods, in partnership with stakeholders, to deter mine the reach, impact, and effectiveness of Planetary Health action.

23. Advocate for political, social, or economic policies and programs, both local and global, that integrate the wellbeing of populations and natural systems.

24. Facilitate approaches that allow communities and groups to articulate their needs and advo cate for the resources and capacities required for Planetary Health action.

25. Appreciate the role that organizing in the community, bottom-up approaches, and movement building has in the political process both locally and globally.

26. Identifies appropriate sources of information to answer population and ecosystem health questions.

27. Exhibit interprofessional values skills that demonstrate respect for, and awareness of, the unique cultures, values, roles/responsibilities, and expertise represented by other professionals and groups that work in Planetary Health.

28. Describe your own understanding of and sense of connectedness to nature.

29. Understand the perspectives of various key stakeholders locally and globally

30. Identify methods for assuring program sustainability.

31. Apply monitoring and evaluation techniques to Planetary Health programs and policies.

32. Translate research findings and other knowledge forms, into policies, community programs, interventions, and public education in a manner that is sustainable, culturally relevant, and economically feasible.

33. Plan, implement, and evaluate an evidence-based program to address a Planetary Health challenge.

34. Propose strategies that achieve "health co-benefits"

35. Demonstrate individual values and life choices that promote well-being, while simultaneously promoting a healthy local and global environment/ecosystem

36. Embrace the principle of transdisciplinarity

37. Display critical self-reflection and cultural and intellectual humility.

38. Apply awareness of cultural values and political systems and practices to the design or imple mentation of policies or programs.

39. Identify stakeholders and build coalitions and partnerships for influencing policy to address Planetary Health challenges.

40. Develop a sense of responsibility to self, community, society, and the natural environment. 
4I. Demonstrate empathy, compassion, integrity, regard, and respect for others in all aspects of professional practice.

42. Integrate community assets and resources to improve the health of humans and the environ ment/planet.

43. Use appropriate evaluation and research methods, in partnership with stakeholders, to deter mine the reach, impact, and effectiveness of Planetary Health actions.

44. Include representatives of diverse constituencies and disciplines in partnerships and foster interactive learning with these partners.

45. Use interpersonal communication skills to facilitate individuals, groups, communities, and orga nizations to improve the health of populations and ecosystems.

46. Discuss multiple dimensions of the policy-making process, including the roles of ethics and evidence-informed policy.

47. Be able to work, and plan, design, and implement interventions under conditions of uncertainty.

48. Understand the role and limitations of impact assessments and current modeling tools.

49. Develop and implement appropriate communication strategies for effective dissemination, that utilize tools of persuasive communication

50. Acknowledge one's limitations in skills, knowledge, and abilities.

51. Apply stakeholder analysis frameworks to understand the relationship among various key stakeholders locally and globally and how that influences Planetary Health outcomes.

52. Influence political and public opinion on Planetary Health issues.

53. Recognize one's own epistemological groundings to effectively interface between distinct knowledge systems

54. Assess needs and assets in partnership with stakeholders.

55. Develop an appreciation for the importance of active listening as a part of effective communi cation.

56. Demonstrate the ability to adapt discipline-specific knowledge, skills, and practice in a re source-constrained setting.

57. Understand the concept and approach of Life-cycle Analysis 